Journal of Geophysical Research: Solid Earth

\section{RESEARCH ARTICLE \\ 10.1002/2017JB015020 \\ Strain Partitioning and Present-Day Fault Kinematics in NW Tibet From Envisat SAR Interferometry}

Key Points:

- We construct a $300 \times 500 \mathrm{~km}^{2}$ continuous LOS velocity map from the Tarim basin to the central part of the Tibetan Plateau

- We develop methodologies to improve data referencing and separate tectonic signal from surface and atmospheric processes -We identify unmapped active structures in the Tarim basin and a distributed gradient of deformation along the Jinsha suture zone

Supporting Information: - Supporting Information S1

Correspondence to:

S. Daout,

simon.daout@ifg.uni-kiel.de

\section{Citation:}

Daout, S., Doin, M.-P., Peltzer, G., Lasserre, C., Socquet, A., Volat, M., \& Sudhaus, H. (2018). Strain partitioning and present-day fault kinematics in NW Tibet from Envisat SAR interferometry. Journal of Geophysical Research: Solid Earth, 123, 2462-2483. https://doi.org/10.1002/2017JB015020

Received 22 SEP 2017 Accepted 14 FEB 2018 Accepted article online 20 FEB 2018 Published online 25 MAR 2018

(O2018. American Geophysical Union. All Rights Reserved.

\author{
Simon Daout ${ }^{1,2}$ iD, Marie-Pierre Doin ${ }^{1}$, Gilles Peltzer ${ }^{3,4}$ (D) Cécile Lasserre ${ }^{1,5}$ iD, Anne Socquet ${ }^{1}$ (D), \\ Matthieu Volat ${ }^{1}$ iD, and Henriette Sudhaus ${ }^{2}$ \\ ${ }^{1}$ Université Grenoble Alpes, Université Savoie Mont Blanc, CNRS, IRD, IFSTTAR, ISTerre, Grenoble, France, \\ ${ }^{2}$ Department of Geosciences, Christian-Albrecht-Universitat zu Kiel, Kiel, Germany, ${ }^{3}$ Department of Earth, Planetary, and \\ Space Sciences, University of California, Los Angeles, CA, USA, ${ }^{4}$ Jet Propulsion Laboratory, California Institute of Technology, \\ Pasadena, CA, USA, ${ }^{5}$ Univ Lyon, Université Lyon 1, ENS de Lyon, CNRS, UMR 5276 LGL-TPE, Villeurbanne, France
}

\section{Introduction}

The present-day tectonics in Asia results from the ongoing India-Eurasia collision, initiated some 50 million years ago. The deformation is characterized by the existence of major active faults, mostly thrusts (as along the Himalayan, the Longmen Shan, and the Qilian Shan fronts that bound the Tibetan Plateau to the south, the east, and the northeast, respectively, or in the Tien Shan farther north) and strike-slip faults (such as the Red River fault in southeastern Asia, the Karakorum Jiali Fault Zone (KJFZ) in southern Tibet, or the Altyn Tagh Fault (ATF), the Kunlun Fault (KF), and the Haiyuan Fault (HF) in northern and eastern Tibet) (Molnar \& Tapponnier, 1975; Tapponnier \& Molnar, 1977; Tapponnier et al., 2001). These long mature faults, which may exceed $1,000 \mathrm{~km}$ in length, are known to produce large-magnitude earthquakes. However, accurately determining their slip rates remains at the heart of the debate on how continents deform (e.g., DeVries \& Meade, 2013; Ge et al., 2015; Mériaux et al., 2012; Wang et al., 2014; Yuan et al., 2013).

A first class of deformation models represents continental deformation as mostly localized on major lithospheric faults, allowing for large continental blocks to move laterally. The Indian and Tarim lithospheric mantles are both considered to subduct under Tibet, reactivating old south and north dipping suture zones (Matte et al., 1996; Mériaux et al., 2004; Peltzer \& Tapponnier, 1988; Tapponnier et al., 1982). In these models, present-day deformation would be accommodated by crustal thickening along accretionary wedges, which decouple crustal blocks and extrude large fragments of continent toward the east along major left-lateral strike-slip faults (e.g., the ATF, the KF, and the HF) (Gaudemer et al., 1995; Lasserre et al., 2002; Meyer et al., 1998; Van Der Woerd et al., 2002). In a second class of models, the deformation of the Tibetan lithosphere is assumed to be continuous and controlled by ductile flow, mostly driven by gravitational forces (England \& Houseman, 1989; England \& McKenzie, 1983; England \& Molnar, 1997a, 1997b). In such models, strike-slip faults play 


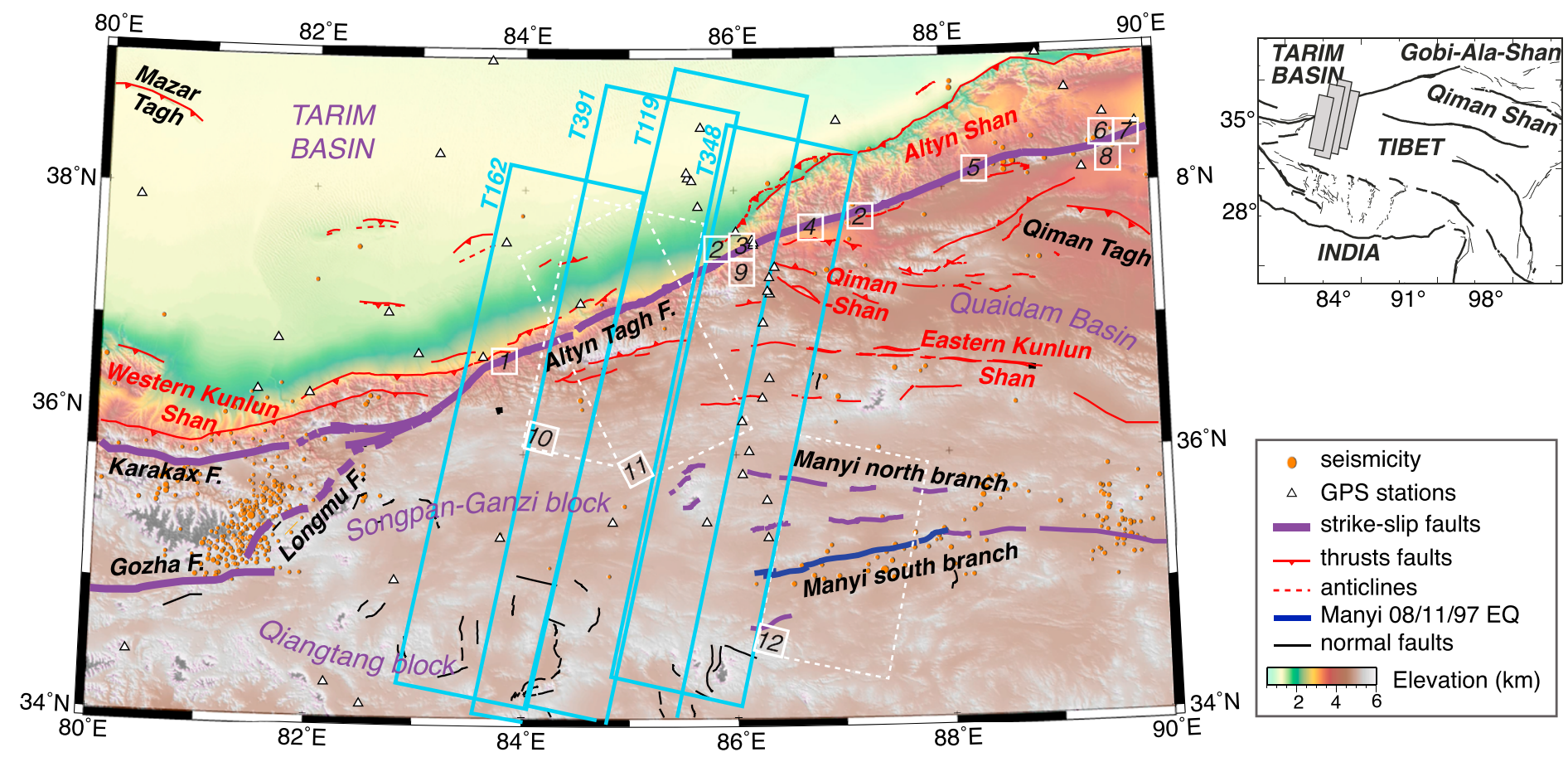

Figure 1. Seismotectonic setting of the Altyn Tagh Fault system superimposed on Digital Elevation Model of the Shuttle Radar Topography Mission (Farr \& Kobrick, 2000). Fault traces are modified from Van Der Woerd et al. (2002) and Replumaz and Tapponnier (2003). Orange dots show the seismicity from 1992 to 2014 from USGS. Black triangles are GPS stations from the Observation Network of China (Wang et al., 2017) and from the GPS transect of He et al. (2013). Surface traces of four overlapping Envisat descending tracks 162, 391, 119, and 348 used in this study are in cyan. Previous interseismic slip rate investigations include Quaternary time scale measurements from offset risers and glacial features from (1) Peltzer et al. (1989) ( 20-30 mm/yr), (2) Mériaux et al. (2004) (27 $\pm 7 \mathrm{~mm} / \mathrm{yr})$, (3) Cowgill (2007) (9.4 \pm 2.3 ), (4) Gold et al. (2009) ( 7-17 mm/yr), (5) Cowgill et al. (2009) (11.5 $\pm 2.5 \mathrm{~mm} / \mathrm{yr})$, and (6) Mériaux et al. (2012) (14 $\pm 1 \mathrm{~mm} / \mathrm{yr}$ ); paleoseismic measurements from (7) Washburn et al. (2001) ( 10-20 mm/yr); GPS transects measurements from (8) Wallace et al. (2004) $(9 \pm 4 \mathrm{~mm} / \mathrm{yr})$ and (9) He et al. (2013) $(9 \pm 4 \mathrm{~mm} / \mathrm{yr})$; and interferometric synthetic aperture radar studies across the Altyn Tagh Fault from (10) Elliott et al. (2008) $(11 \pm 10 \mathrm{~mm} / \mathrm{yr})$ and from (11) Zhu et al. (2016) $(8 \pm 0.7 \mathrm{~mm} / \mathrm{yr})$, as well as across the MF, which broke during the $1997 \mathrm{M} 7.6$ earthquake (blue line), from (12) Bell et al. (2011) $(3 \pm 2 \mathrm{~mm} / \mathrm{yr})$.

a minor role in accommodating the continental shortening (e.g., Bendick et al., 2000; Wallace et al., 2004; Wright et al., 2004; Zhang et al., 2004). Yet another class of models describes the presence of a low-viscosity layer ( $<10^{18} \mathrm{~Pa}$ s) within the crust due to increased radiogenic heat production in thickened crust (Clark \& Royden, 2000; Cook \& Royden, 2008; Royden et al., 1997). This low-viscosity layer would result in significant mass transport in response to pressure gradient. This "channel" would flow more easily than either the overlying brittle upper crust or the underlying mantle lithosphere, transporting material and contributing to the growth of the flat topography. Low-viscosity layers, potentially transient, have been evidenced by interferometric synthetic aperture radar (InSAR) measurements on some parts of the Tibetan Plateau from far-field postseismic displacements (Huang et al., 2014; Ryder et al., 2007, 2011; Wen et al., 2012) or by lake surface and level changes (Doin et al., 2015). However, they suffer from trade-offs between the viscosity and the depth of the deformation and from our poor knowledge of the steady state rheology of the crust at longer time scales (e.g., DeVries \& Meade, 2016; Leloup et al., 1999).

InSAR data provide unique information to characterize the present-day deformation of Tibet, in particular in western and central Tibet, where GPS data are critically sparse (e.g., Liang et al., 2013; Wang et al., 2017). Major faults such as the ATF, the KF, and the KJFZ fault systems are therefore poorly covered by GPS network in the near field (Figure 1). InSAR provides continuous maps of deformation throughout broad regions and therefore precisely constrains the fault's interseismic loading and its lateral variations. However, because of many data processing challenges, only a few studies attempted to measure interseismic deformation in the western part of Tibet (e.g., Bell et al., 2011; Elliott et al., 2008; Garthwaite et al., 2013; Jolivet et al., 2008; Wang \& Wright, 2012; Wright et al., 2004; Zhu et al., 2016). 
With its remarkable morphology and $4 \mathrm{~km}$ of relief, the ATF is the main active structure along the northern boundary of the Tibetan Plateau (Cheng et al., 2016; Jolivet et al., 2001; Matte et al., 1996; Molnar \& Tapponnier, 1975; Peltzer et al., 1989; Yin \& Harrison, 2000) (Figure 1). If stable for a long period of time, a high slip rate on the ATF would accommodate a large part of the India-Asia convergence (Avouac \& Tapponnier, 1993; Mériaux et al., 2004; Mériaux et al., 2004, 2005, 2012; Peltzer \& Saucier, 1996; Peltzer et al., 1989; Washburn et al., 2001; Xu et al., 2005). It would only leave negligible convergence within Tibet and transfer most of the convergence to the thrust and fold systems in the Qaidam basin and the Qilian Shan (Jolivet et al., 2008; Lasserre et al., 2007; Tapponnier et al., 2001). Conversely, a low rate on the ATF would require some deformation distributed through the plateau and possibly larger slip rates on some other secondary faults (Bendick et al., 2000; Cowgill, 2007, 2009; Gold et al., 2009; He et al., 2013; Wallace et al., 2004; Zhang et al., 2004; Zhu et al., 2016) (Figure 1).

In this paper, we focus on the northwestern part of the Tibetan Plateau between longitudes $83^{\circ}$ and $87^{\circ}$ (Figure 1). We processed four $100 \mathrm{~km}$ wide Envisat descending tracks from the Tarim basin, north of the ATF, to the central part of Tibet covering the western termination of the Manyi Fault (MF), which ruptured during the 1997 M 8 Manyi earthquake (Funning et al., 2007; Peltzer et al., 1999; Ryder et al., 2007; Wang et al., 2007). For most of this section $\left(83^{\circ}-86^{\circ}\right)$ the ATF is relatively simple with a single branch at the foot of the large topographic step between Tibet and the Tarim basin (Figure 1). East of $86^{\circ}$, the ATF enters zones of higher topography between the Altyn Shan to the north and the Qiman Shan to the south. Both these ranges are compressional structures with an active thrust along the northern front of the Altyn Shan and smaller thrust faults branching off to the south. West of $83^{\circ}$, the ATF enters the western Kunlun range and branches into a thrust system at its northern front and the left-lateral Longmu-Gozha Fault to the south (Figure 1). Quaternary deformation of sediments along the southern edge of the Tarim basin confirms the convergence between the Tarim and Tibetan blocks (Matte et al., 1996; Jiang et al., 2013). The thrust-system foreland extends to the Mazar Tagh range along a décollement rooting on the ATF that reaches up to the middle part of the Tarim basin over a width of about $500 \mathrm{~km}$ (Coudroy et al., 2009; Guilbaud et al., 2017; Wittlinger et al., 2004) (Figure 1). Recent earthquakes, such as the $2015 M_{w} 6.4$ Pishan earthquake that broke a blind thrust north of the western Kunlun Shan, are evidence of the strain accumulation along these deep thrust systems (Lu et al., 2016; Sun et al., 2016), which now need to be considered in kinematic models.

In this study, we develop methodologies to address InSAR processing challenges and separate the tectonic signal from surface and atmospheric noise processes. We produce a line-of-sight (LOS) velocity map covering a broad region in the northwestern part of the Tibetan Plateau, shedding light on the kinematics of the western part of the ATF and associated faults. We then provide quantitative estimates of the loading rate and the range of geometries consistent with surface velocities observed by InSAR and GPS using a Bayesian framework and assuming conservation of motion across the fault network.

\section{InSAR Processing}

\subsection{State of the Art}

InSAR is a powerful tool to map precisely and over large areas surface displacements (e.g., Bürgmann et al., 2000; Hooper et al., 2012). This technique has been widely employed in earthquake and fault studies (e.g., Jolivet et al., 2013; Pathier et al., 2003; Rousset et al., 2016; Sudhaus \& Jónsson, 2011; Wimpenny et al., 2017), volcanic dike intrusions (e.g., Cervelli et al., 2002; Grandin et al., 2009; Manconi \& Casu, 2012; Pedersen \& Sigmundsson, 2006), landslide monitoring (e.g., Fruneau et al., 1996; Hilley et al., 2004; Schlögel et al., 2015; Strozzi et al., 2013; Wasowski \& Bovenga, 2014), urban subsidence (e.g., Amelung et al., 1999; Bawden et al., 2001; Fruneau \& Sarti, 2000; López-Quiroz et al., 2009), permafrost freeze-thaw cycles (e.g., Chang \& Hanssen, 2015; Daout et al., 2017; Liu et al., 2010; Short et al., 2011), or water vapor mapping (e.g., Hanssen et al., 1999; Wadge et al., 2002). However, for small deformation signals in high mountainous areas, such as interseismic deformation, the approach suffers from major limitations due to high topographic gradients and unsuitable valley flank orientations relative to the synthetic aperture radar (SAR) view angle, snow cover, or atmospheric delays. Within the Tibetan Plateau, Taylor and Peltzer (2006) measured by InSAR the surface velocity field associated with the Gyaring Co fault and quantified a localized surface displacement along conjugated faults. They first pointed out the difficulties associated with the deformation induced by freeze and thaw cycles and the atmospheric delay changes across the topographic steps (Figure S1 in the supporting information). Elliott et al. (2008), Jolivet et al. (2008), Wang and Wright (2012), Wright et al. (2004) and Zhu et al. (2016) quantified the interseismic surface displacements associated to the ATF (Figure 1) but faced the numerous ambiguities 
and trade-offs between the tectonic deformation and topography, phase delays associated with stratified troposphere, or orbital ramps. To deal with these problems, Elliott et al. (2008) or Wang and Wright (2012) inverted InSAR maps, solving simultaneously for parameters describing the nontectonic processes and the slip rates on faults. This resulted in large uncertainties on the velocity gradients across fault due to the strong trade-off between the different parameters (Figure S1b). Moreover, due to the radar phase coherence loss along the sand dunes in the south of the Tarim basin and in some sedimentary basins within the plateau, these previous studies are restricted to using data in the near field of the ATF, although the far-field signal is important to accurately constrain fault slip rate. Bell et al. (2011) measured $3 \pm 2 \mathrm{~mm} / \mathrm{yr}$ of interseismic motion across the MF prior to the 1997 earthquake (Figure 1), but the high level of noise reveals the importance of taking into account surface processes affecting the coherence of the interferometric phase. Wang and Wright (2012) and Garthwaite et al. (2013) describe the first attempts to process long radar tracks across the Tibetan Plateau. There again, coherence loss and the contribution of atmospheric signal limited the possibility to resolve tectonic rates without ambiguities in all areas. For example, Wang and Wright (2012) did not unwrap the interferometric phase across the ATF and studied separately the northern and the southern parts of the fault.

\subsection{Data Set and Formation of Wrapped Interferograms}

We processed the complete Envisat descending archive along four $500 \mathrm{~km}$ long and $100 \mathrm{~km}$ wide Envisat overlapping tracks $(162,391,119$, and 348) between 2003 and 2011 (Figure 1). To obtain displacement time series in this natural environment and limit the effects of phase decorrelation, we constructed 484 small baseline differential interferograms with the New Small Baselines Subset chain (NSBAS) (Doin et al., 2011, 2015) based on the ROI_PAC software (Rosen et al., 2004).

Single Look Complex images are computed from the raw radar data in a common mean Doppler geometry. Single Look Complex images are resampled to a single master image geometry, and a slope-dependent range spectral filter is applied to increase the coherence in interferograms with long perpendicular baselines (Guillaso et al., 2006). A network of SAR image pair combinations is defined using spatial and temporal baseline constraints ensuring redundancy (Figure S2). Interferograms are formed with two range looks and 10 azimuth looks $\left(\sim 40 \times 40 \mathrm{~m}^{2}\right)$ to obtain coarser differential interferograms, and a linear ramp in range is removed to account for orbital errors and clock drift (Fattahi \& Amelung, 2014; Lauknes et al., 2011; Zhang et al., 2014). Removing such linear ramp may not necessarily remove orbital errors as long wavelength tectonic signals can trade off against the ramp (Biggs et al., 2007). Therefore, a second ramp will be removed later to account for this during the modeling. InSAR-derived deformation maps are thus exempt of any uniform tilt in range. Finally, the signal-over-noise ratio (SNR) of the wrapped differential interferograms is improved by correcting local digital elevation model (DEM) errors exploiting the phase versus perpendicular baseline relationship (Ducret et al., 2014). The correction reduces up to $20 \%$ the wrapped phase variance on interferograms, limiting apparent phase decorrelation in areas of high relief (Figures S3 and S4).

\subsection{Atmospheric Delays Correction}

The atmospheric radar phase delay is divided into a turbulent component and stratified component, which correlates with the topography(Hanssen, 2001). The spatial phase patterns produced by the turbulent atmosphere being random both in space and time can be attenuated by smoothing the time series. In contrast, the stratified tropospheric phase delay shows smooth variations in time and is dominated by a seasonal term (Cavalié et al., 2007; Doin et al., 2009; Fattahi \& Amelung, 2015) with an amplitude depending on variation of temperature, pressure, and relative humidity. The stratified tropospheric delay in interferograms can reach few centimeters per kilometer of elevation and often overprints any small deformation. Correcting this signal is thus one of the most important processing steps, first, to prevent unwrapping errors in mountainous areas and, second, to reach an accuracy of a few millimeters per year on ground velocities.

Two classes of methods have been developed to correct for the tropospheric phase delay. The first one empirically exploits the correlation between the interferometric phase and the elevation (Béjar-Pizarro et al., 2013; Bekaert et al., 2015; Cavalié et al., 2008; Doin et al., 2015; Lin et al., 2010; Shirzaei \& Burgmann, 2012; Tymofyeyeva \& Fialko, 2015) (Figure S5). These approaches are effective at reducing the interferometric phase variance but may remove some displacement-related signal when deformation correlates with topography. This is a critical issue for the Tibetan margin because of the $4 \mathrm{~km}$ topographic step between the Tarim basin and the high plateau, colocated with the expected gradient of surface displacement associated with slip on the ATF (Figure S1b). We show, in a synthetic test, that the simulated signal produced by interseismic strain 
along a strike-slip fault aligned with the ATF can be partly or entirely removed by applying a correction based on empirical phase-topography correlation, depending on the parametrization used (supporting information Figure S6).

The second class of atmospheric correction method consists in estimating the phase delay using auxiliary data such as GPS delay measurements (Li et al., 2006; Webley et al., 2002; Williams et al., 1998), satellite multispectral imagery (Li et al., 2012), meteorological data (Delacourt et al., 1998), or global atmospheric models (Doin et al., 2009; Jolivet et al., 2011, 2014). In this study, we estimate the phase delay due to the stratified troposphere using the global atmospheric reanalysis model ERA-Interim (ERA-I) from the European Centre for Medium-Range Weather Forecasts (Dee et al., 2011). ERA-I provides estimates of temperature, water vapor partial pressure, and geopotential height every $6 \mathrm{~h}$ at 37 pressure levels on a $0.7^{\circ}$ grid from 1989 to present (Dee et al., 2011). Integrated path delays at acquisition times, computed from both hydrostatic and wet delay contributions, are derived at ERA-I points encompassing a SAR scene, using vertical profiles of these variables. The delay is then mapped on the radar scene using a DEM. When several ERA-I points are used, bilinear interpolation in the horizontal direction is performed on the vertical profiles. However, in the presence of steep topography, interpolating model parameters between grid nodes at largely different elevations can produce artifacts in the phase delay maps because the weather model must be extrapolated below the surface of the Earth. To avoid this problem, we compute the atmospheric phase delay maps using ERA-I parameter values from the node with the lowest elevation within the radar scene (Doin et al., 2009) (Figure S7). This correction is validated by comparison with empirical estimations (supporting information). In the following section we assess the possible error on the atmospheric phase delay correction. Our objective is to provide an error bound on the LOS surface velocity due to the atmosphere.

\subsection{Uncertainties on Velocity Maps Due To Stratified Atmospheric Delays}

Velocity maps are known to be polluted by aliasing of oddly sampled time-varying atmospheric signals (Doin et al., 2009). To analyze the impact of the atmospheric correction on the expected velocity map, we compare the 1 day resolution time series of the phase delays predicted by ERA-I at two points (two ERA-I nodes in Figure S2), in the overlapping area of the two tracks 119 and 391 . One is located in the Tarim basin $\left(38.25^{\circ} \mathrm{N}\right.$, $\left.85.5^{\circ} \mathrm{E}\right)$, at the lowest elevation (altitude of $\left.1.4 \mathrm{~km}\right)$, and the other one is in the Tibetan Plateau $\left(36.75^{\circ} \mathrm{N}\right.$, $85.2^{\circ} \mathrm{E}$ ), closest to the ATF, at an altitude of $4.5 \mathrm{~km}$ (Figures 2 and S7). We simulate fictitious velocity maps calculated solely with the ERA-I delay prediction over the topography of the Tibetan Plateau at SAR acquisition time (Figure S9). We use 7 day moving windows to compute an average time series $S_{7 d}$ and a standard deviation $\sigma_{k}$. The justification of this 7 day moving average is based on the comparison with empirical estimates (Figure S8). It is large enough to bracket extreme dry or wet events but small enough to keep the temporally correlated variability.

We observe within the Tarim basin (Figure $2 \mathrm{a}$ ) a strong daily variability of $\sim 6.5 \mathrm{rad}(=\sim 29 \mathrm{~mm}$ ) and a small seasonality of $\sim 2.5 \mathrm{rad}(=\sim 5.5 \mathrm{~mm})$ in amplitude, while within the Tibetan Plateau (Figure $2 \mathrm{~b})$, the ERA-I model predicts a regular seasonal signal of $\sim 8 \mathrm{rad}(=\sim 17 \mathrm{~mm})$ in amplitude and a higher daily variability in summer $(\sim 5 \mathrm{rad}=\sim 22 \mathrm{~mm}$ ) than in winter $(\sim 1.5 \mathrm{rad}=\sim 7 \mathrm{~mm}$ ). The delay differences (Figure $2 \mathrm{c}$ ) show a slight seasonal signal of $\sim 6 \mathrm{rad}(=\sim 13.5 \mathrm{~mm})$ of amplitude and a strong daily variability of $5.5 \mathrm{rad}$ $(=\sim 24.5 \mathrm{~mm}$ ). The delays at acquisition dates (shown with red circles in Figure 2 ) are sometimes clearly outside the $\sigma_{k}$ envelope.

Because of the few control points of air moisture in this remote area, ERA-I may not well predict the very quick variations in delay that are associated to abrupt changes in humidity and, to a lesser extent, in temperature. We thus use the 7 day standard variations, $\sigma_{k=i}$, centered on the date $i$, as a proxy for errors in ERA-I prediction. Furthermore, some computed delays that appear as outliers in the time series may be more prone to an erroneous prediction by ERA-I. We therefore define a proxy, $\sigma_{p, i}$, for the uncertainty on $S_{i}$ for each acquisition date $i$, such as

$$
\begin{gathered}
\sigma_{p, i}=\sigma_{k=i}, \text { if }\left|S_{i}-S_{7 d}\right|<\sigma_{k=i}, \\
\sigma_{p, i}=\left|S_{i}-S_{7 d}\right|, \text { otherwise. }
\end{gathered}
$$

In short, if the daily acquisition, $S_{i}$, is close to the sliding window average model, $S_{7 d}$, and within the envelope, $\sigma_{k}$, then the error, $\sigma_{p, i}$ is equal to the standard deviation at the date $i, \sigma_{k=i}$. Otherwise, if the daily acquisition, $S_{i}$, is an outlier (i.e., $\left|S_{i}-S_{7 d}\right|>\sigma_{k=i}$ ) then the error, $\sigma_{p, i}$, is equal to its absolute distance to the average. 


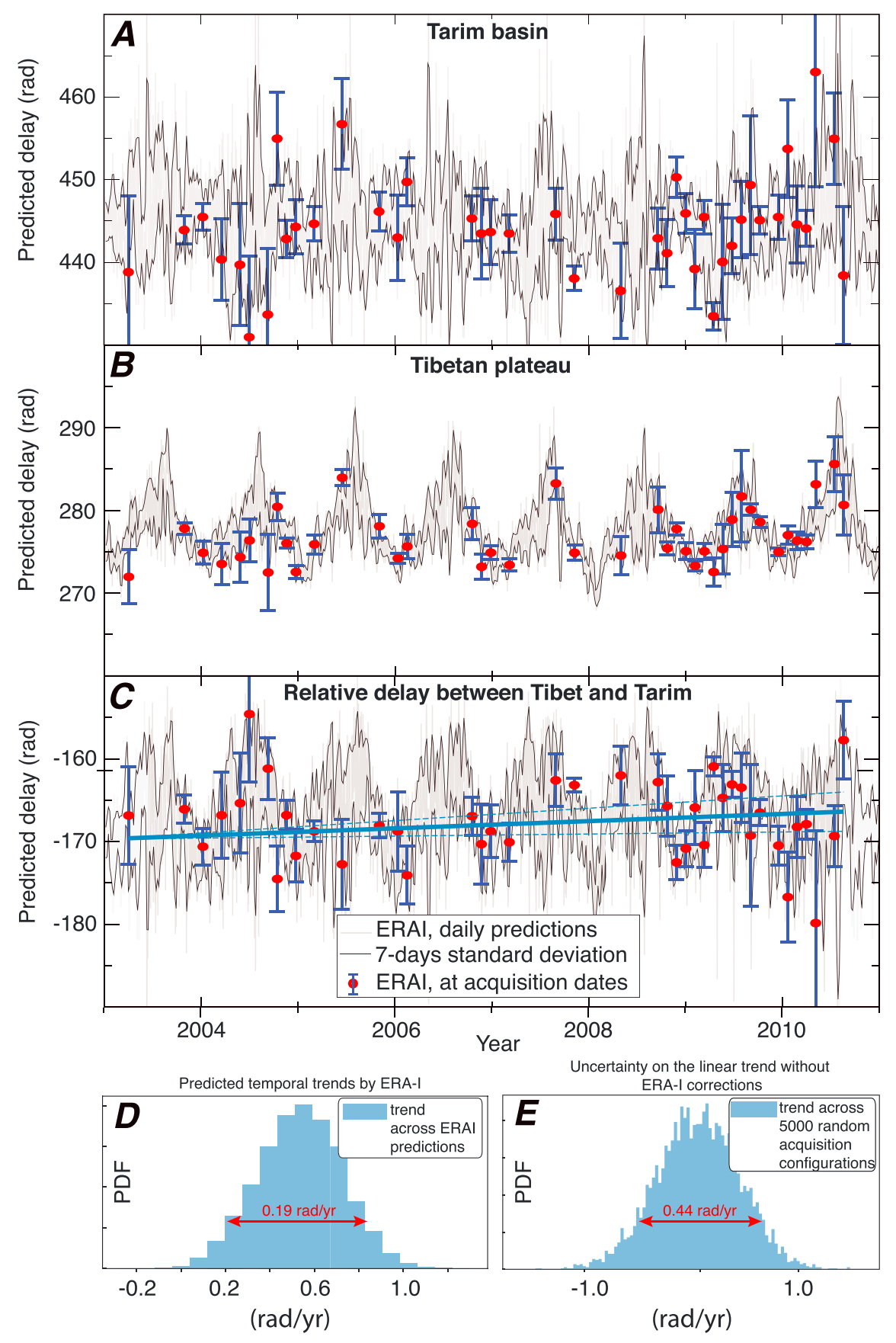

Figure 2. Predicted phase delay time series from ERA-Interim atmospheric model, $S_{k=i}$ (red circles), plotted as a function of time superimposed to the daily model (gray lines) and the 7 day sliding windows standard deviation $\sigma_{k}$ (black lines). (a) Relative delay in between the satellite and the Tarim basin $\left(38.25^{\circ} \mathrm{N}, 85.5^{\circ} \mathrm{E}\right)$ located at $1,400 \mathrm{~m}$ height. (b) Relative delay in between the satellite and the Tibetan Plateau $\left(36.75^{\circ} \mathrm{N}, 85.2^{\circ} \mathrm{E}\right)$ located at $4,500 \mathrm{~m}$ height. (c) Relative delay in between the Tibetan Plateau and the Tarim basin (two ERA-I nodes in Figure S5) with associated error bar proxies, $\sigma_{p, i}$. (d) Predicted temporal trend, $\Delta v$, and uncertainties, $\sigma_{\Delta v}^{\text {ERA-I }}$ across the Altyn Tagh Fault due to the atmosphere from ERA-I models weighted by the defined error proxy. (e) Computed uncertainty, $\sigma_{\Delta v}$, between Tibet and Tarim, if no atmospheric corrections were applied. 
The error bar proxies on the absolute and relative delays are drawn in Figure 2. Note that a few acquisitions have a $\sigma_{p, i}$ value clearly larger than others. We assume that their ERA-I corrections are less reliable than for other acquisitions. Note also that the average $\sigma_{k}(\sim 2.1 \mathrm{rad}=\sim 9.5 \mathrm{~mm})$ is lower than the absolute $S$ variability by a factor of 3 ( $\sim 5.9 \mathrm{rad}$ ). Empirically derived phase-elevation relationships (Figure S8) show that $\sigma_{p, i}$ error proxy corresponds to an upper bound on the $1 \sigma$ error on ERA-I-derived delays. This proxy is thus a conservative estimate of errors on ERA-I that allows to include all empirical measurements. In the following time series analysis, these ERA-I-derived uncertainties are used to weight each acquisition and thus better constrain the linear trend across the ATF due to the aliasing and variability of the tropospheric seasonal signal.

From this analysis, we can draw the following conclusions regarding the uncertainty on the relative velocity across the ATF. First, if the data were not corrected from stratified atmospheric delays, we would expect a temporal bias, $\Delta v$, corresponding to the temporal trend in rad/yr across the $S_{i}$ values. To quantify statistically this potential bias, if no atmospheric corrections were applied (Figure 2e), we randomly sample the daily model $S_{i}$ 5,000 times (keeping the spread of the actual Envisat sampling) and compute the temporal linear trend at each iteration. The predictions show a gaussian distribution centered on 0 with an uncertainty, $\sigma_{\Delta v}$, of $0.44 \mathrm{rad} / \mathrm{yr}$ $=1.96 \mathrm{~mm} / \mathrm{yr}$. Second, we can infer that the sign and amplitude of this trend will strongly depend on the data sampling within the seasonal cycle (relatively random). We finally compute the velocity gradient due to the atmosphere, $\Delta v$, from the ERA-I predictions at acquisition dates (blue line in Figures $2 c, 2 d$, and S10) and derived its uncertainty, $\sigma_{\Delta v}^{\text {ERA-I }}$ (blue dashed lines in Figures $2 c, 2 d$, and S10) by propagating the defined error proxy at each acquisition date into an error on the linear trend. To summarize, the ERA-I corrections impact the relative velocity observed across the ATF by -1.85 to $2.45 \mathrm{~mm} / \mathrm{yr}$ across the $\sim 3 \mathrm{~km}$ of topography, with a conservative uncertainty on the velocity of $0.8-1.3 \mathrm{~mm} / \mathrm{yr}$ on the four studied tracks (Figure S10). The ERA-I correction thus reduces the uncertainty on the velocity across the Tibet border by a factor of 2 .

\subsection{Unwrapping Procedure of the Interferometric Phase}

South of the ATF, the plateau is shaped by narrow, E-W mountain ranges reaching elevations of $\sim 6,000 \mathrm{~m}$, bounding quaternary sedimentary basins at an elevation of $\sim 4,400 \mathrm{~m}$. These sedimentary basins contain soils with permanent ice, called permafrost, with an active layer affected by the seasonal freeze-thaw cycle, resulting in the upheaval and subsidence of the soil and other cryoturbations processes that degrade the coherence of the radar signal. As described in Daout et al. (2017) and in the supporting information, we implement a specific method to unwrap the interferometric phase delay, that consists in removing a spatial template of deformation to help the unwrapping across the sedimentary basins where we observe strong phase gradients. This approach is standard in InSAR processing and has already been applied for land subsidence (e.g., López-Quiroz et al., 2009; Strozzi \& Wegmuller, 1999) or volcanic (e.g., Pinel et al., 2008; Yun et al., 2007) studies in presence of complex and large surface displacements. Here we extract the template from a principal component analysis decomposition of a series of well unwrapped interferograms (Figure S11). We also apply different phase filters, which are a weighted average of the interferometric phase in sliding windows, to help the unwrapping across the alluvial fans and sand dunes, north of the ATF (Figure S12) (Grandin et al., 2012; Pinel-Puyssegur et al., 2012). Doing so, we successfully unwrap interferograms from north to south. Finally, checking misclosure in the interferometric network allows to identify remaining unwrapping errors and correct them manually (López-Quiroz et al., 2009).

\subsection{Residual Orbit Errors and Time Series Analysis}

Before constructing the time series of the LOS displacement observed by InSAR, it is important to define a reference frame (Figure S13). The observation of the interferograms of northwestern Tibet (Daout et al., 2017) showed that the observed phase change contains the tectonic signal along active faults, the seasonal signal associated with the freeze-thaw cycle of the permafrost active layer in basins, and overall ramps due to residual orbit clock drift errors. Here we refer all interferograms with respect to the bedrock in the area between the ATF and the western termination of the MF (Figure 1). The bedrock reference frame is defined by masking the sedimentary basins where a strong (larger than $>2.5 \mathrm{~mm}$ ) seasonal signal is observed (Daout et al., 2017). The referencing is done as follows. For each interferogram, one azimuthal ramp is adjusted to the bedrock pixels. The ramp is generally quadratic in both azimuth and range for long interferograms, or linear for short interferograms with missing frames. The ramps are then optimized in the network of interferograms to ensure internal consistency. Finally, the optimized, reconstructed ramps are removed from each interferogram (supporting information section S4.2). 


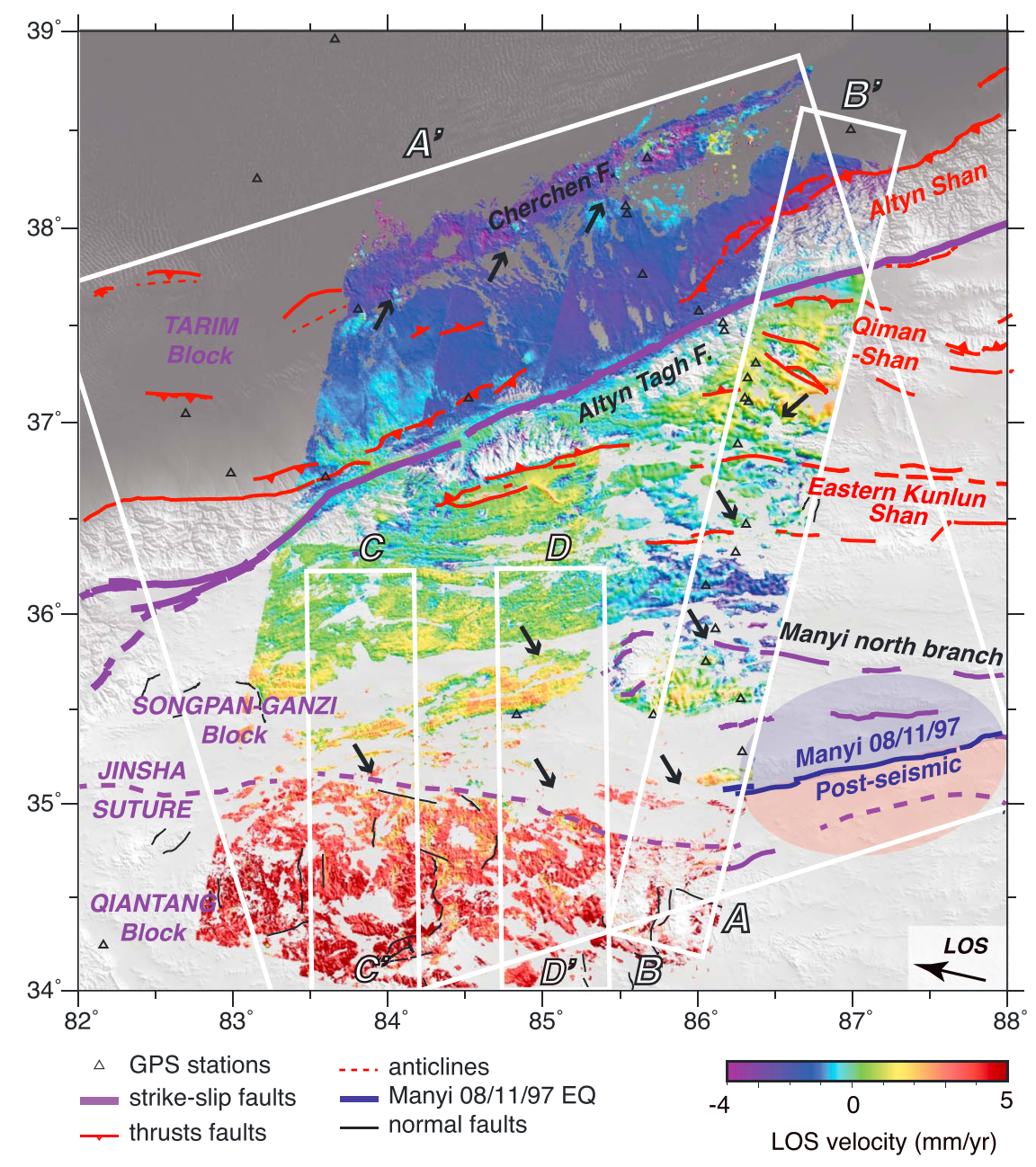

Figure 3. Line-of-sight (LOS) velocity map of the four tracks 162, 391, 119, and 348 displayed for an average incidence angle of $23.5^{\circ}$ and referred to the area located between the ATF and the Jinsha suture. Fault traces and GPS stations as in Figure 1. Surface trace of the suture zone is from Taylor and Yin (2009). Black arrows point out gradients of deformation. Positive motion is toward the satellite. Blue (motion away from the satellite) and red (motion toward the satellite) ellipse is a schematic representation of the postseismic of the Manyi Earthquake according to Ryder et al. (2007). $A A^{\prime}, B^{\prime}, C C^{\prime}$, and $D^{\prime}=$ four profiles across observed velocity gradient described in Figures 4 and 8.

Time series of LOS displacement are then constructed using the NSBAS method (Doin et al., 2015) with a linear regularization function of the form

$$
\phi_{i}=V \times t_{i}+\alpha B_{\perp}^{i}
$$

where $\phi_{i}$ is the pixel phase change between time $t$ and the first epoch, $V$, the best estimate of the pixel LOS velocity, $\alpha$, an estimate of the residual DEM error, and $B_{\perp}^{i}$ is the perpendicular baseline of acquisition $i$. Maps of DEM error coefficients display typical oblique striations and are consistent between overlapping areas (Figure S14) at short-wavelength (with some residual long-wavelength ramps between adjacent tracks). Note that for Envisat data the velocity estimation does not trade off with the DEM error correction as the perpendicular baseline does not drift with time (Figure S2). Each equation set (3) is weighted by the inverse of the ERA-I correction uncertainty, $\sigma_{p, i}$, obtained for each image, $i$ (section 2.4).

The same processing is applied to all four tracks. To combine all velocity maps in a single map (Figure 3), we started by referencing the velocity field of the central track (119) to the bedrock pixels located south of the ATF and north of the Jinsha suture with a linear adjustment in azimuth. Then, the LOS velocity maps of the three other tracks were adjusted with respect to one another by adding the ramp in azimuth that minimizes the difference in the overlapping areas between adjacent tracks (Figure S15). Because the surface displacements 

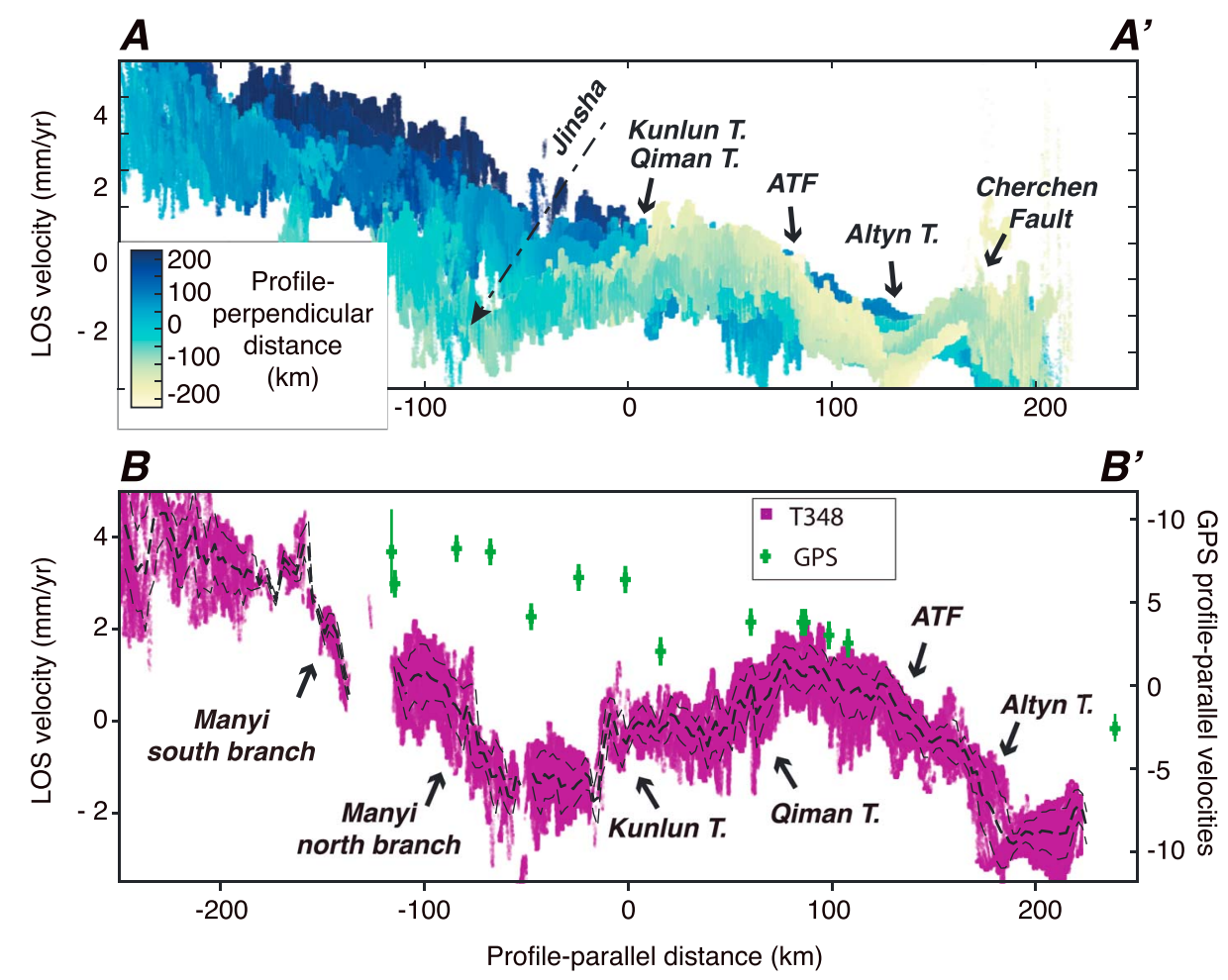

Figure 4. Line-of-sight (LOS) velocity of two stack profiles across active structures in NW Tibet. See Figure 3 for location. $\mathrm{AA}^{\prime}=$ Altyn Tagh Fault (ATF)-perpendicular profile encompassing the four tracks. Color scale depending on the along-ATF distance (blue = west, yellow = east). Arrows point to five velocity gradients associated with Jinsha suture, Qiman-Kunlun thrusts, ATF, Altyn Shan thrusts, and the Cherchen Fault. BB ${ }^{\prime}=$ profile perpendicular to Qiman Shan and along the azimuth of the track, extending from Tarim basin to southern branch of Manyi Fault. Green crosses = GPS velocities projected along the B-B' profile, that is, oblique to the ATF strike (see section 4.1 for GPS data processing). Arrows point to six velocity gradients associated with southern and northern branches of the Manyi Fault, Kunlun thrusts, Qiman Shan thrusts, ATF, and Altyn Shan thrusts.

are expected to be mostly horizontal along the strike-slip system, we normalize velocity maps to a constant incidence angle of $23.5^{\circ}$. This is done by scaling the LOS velocity of each track by $\sin \left(23.5^{\circ}\right) / \sin (\theta)$, where $\theta$ is the local incidence angle. Note that this harmonization is only used for map visualization of section 3 and not for the following modeling part in section 4.2. The discrepancy of the normalized LOS velocities in overlapping areas between adjacent tracks (e.g., Wen et al., 2012) is of $0.4-0.8 \mathrm{~mm} / \mathrm{yr}$ (Figure S15c).

\section{LOS Velocity Field in Northwestern Tibet}

The final LOS surface velocity map shows for the first time an almost continuous view of the surface displacement field over a broad area $(300 \mathrm{~km} \times 500 \mathrm{~km})$ in NW Tibet that remains largely uncovered by GPS data (Figure 3). Areas where large seasonal movements associated with the permafrost active layer are observed have been masked for clarity. The first-order features of the velocity field are the steep gradient across the ATF showing the overall eastward movement of Tibet (red-yellow tones, toward the satellite) with respect to the Tarim block (blue tones, away from the satellite), and a distributed gradient along an east-west trend at the latitude of the Jinsha suture (Figures 3 and 4). In addition, a zone of relatively low velocity is observed in the eastern part of the covered area between the eastern Kunlun Shan and the northern branch of the MF (Figure 4). These features are observed in the decadal linear trends of the InSAR time series and most likely represent tectonic surface displacements associated with the active faults in NW Tibet. At a more detailed level, deformation is also visible north of the ATF, along the southern rim of the Tarim basin (Figure 5).

\subsection{Transpressional Deformation Along the Northern Edge of Tibet}

The LOS surface velocity difference of $\sim 3-4 \mathrm{~mm} / \mathrm{yr}$ observed between the northern Tibet bedrock and the southern Tarim is consistent along the $300 \mathrm{~km}$ wide section covered by the four radar tracks used in this study. 

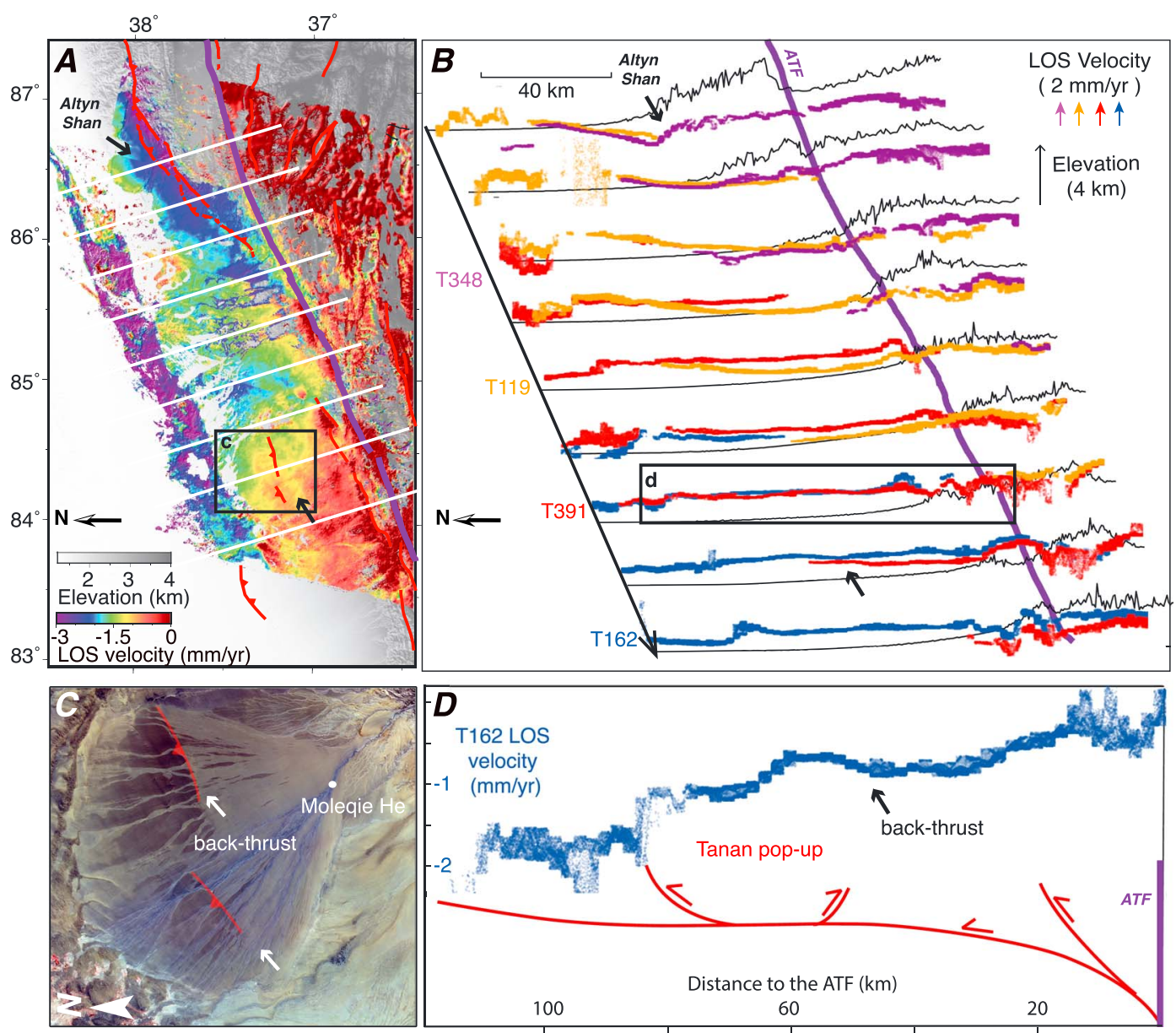

Figure 5. (a) Zoom on Figure 3 in the foreland of the Tibetan Plateau south of the Tarim basin. (b) Topographic (dark lines) and line-of-sight (LOS) velocities (purple $=$ track 348, orange $=$ track 119, red $=$ track 391, and blue $=$ track 162) profiles perpendicular to the Altyn Tagh Fault (ATF). The white lines in (a) indicate the location of the nine $160 \mathrm{~km}$ long and $20 \mathrm{~km}$ large profiles. (c) Zoom around a north dipping thrust fault cutting an alluvial fan in the Tarim basin (black rectangular box annotated (c) in panel (a) from an ASTER multiband image. (d) LOS velocity profile from track 162 (blue dots) within the Tarim basin across the north dipping and south dipping thrusts (black rectangular box annotated (d) in panel (b) with interpreted fault structures. Black and white arrows point out observed velocity gradients in the Tarim basin.

The surface velocity gradient occurs within a $30 \mathrm{~km}$ wide zone along the active trace of the ATF (Figures 3 and 4). We interpret this signal primarily as the elastic displacement rate associated with the left-lateral movement on the deep part of the ATF.

Around longitude $\sim 86^{\circ}$, the data indicate velocity changes associated with the slight change of azimuth of the ATF and its connection with the Qiman Shan and eastern Kunlun Shan thrusts, $70 \mathrm{~km}$ south of the ATF (Profile BB' in Figure 4). Approximately $1 \mathrm{~mm} / \mathrm{yr}$ of velocity change is observed, a gradient consistent with that produced by interseismic strain across a north dipping thrust, south of the Qiman Shan. Similarly, the strong velocity gradient with opposite sign observed $40 \mathrm{~km}$ north of the ATF could be associated with the south dipping Altyn Shan thrusts (Figures $4 \mathrm{~b}$ and $5 \mathrm{a}$ ). This displacement exhibits a linear temporal evolution in the InSAR time series, indicating that a tectonic origin is more likely than a hydrological process. In addition, Google Earth images show that the recent deposits and drainage at the foot of the Altyn Ranges are disrupted by active thrusts.

The InSAR data also show a sharp step in velocity along a linear structure at the base of the alluvial fans along the foreland of Tibet (Figures 3, 4 (Profile $A A^{\prime}$ ), and 5), referred to as the Cherchen Fault in previous studies (Yin \& Harrison, 2000). We ruled out any unwrapping errors or hydrological deformation in this area by checking for the absence of misfit misclosure and seasonal behavior in the time series analysis. 
Assuming a tectonic origin of the deformation, the velocity gradient can be related to either left-lateral shear or uplift above a south dipping thrust. The velocity profiles across this structure indicate a LOS velocity decrease to the north by $0.2-0.6 \mathrm{~mm} / \mathrm{yr}$ (Figure 5). Furthermore, the profile in Figure $5 \mathrm{~d}$ shows a slight gradient in the opposite sign $20-25 \mathrm{~km}$ south of the linear structure. These changes in velocity are aligned and probably associated with thrust faults mapped along the southern rim of the Tarim basin from the analysis of seismic profiles (Laborde, 2017). The structure is a continuous, south dipping thrust fault affecting basement rocks under the Cenozoic sediments in southern Tarim. The more subdued signal observed south of the main structure (centered at $37.4^{\circ} \mathrm{N}, 84.4^{\circ} \mathrm{E}$ ) corresponds to a north dipping, back-thrust fault that reaches the surface across the Moleqie River fan, clearly visible in the Advanced Spaceborne Thermal Emission and Reflection Radiometer (ASTER) visible and near-infrared enhanced image shown in Figure 5c. The image highlights the older terraces of the fan uplifted with respect to the active channels (Laborde, 2017). Together, the south dipping and north dipping faults form the Tanan pop-up structure lifting up a 20-25 km wide portion of crust. We interpret both changes in LOS velocity in this area to be the result of the vertical movement associated with the thrust faults currently locked in the upper part of the crust (Figure 5d). These findings indicate that the northern edge of Tibet along the studied section is a transpressional boundary with left-lateral motion parallel to the ATF and convergence perpendicular to it. In continuity but with less intensity than the convergence observed north of the Kunlun ranges (Guilbaud et al., 2017; Lu et al., 2016; Matte et al., 1996; Sun et al., 2016), the shortening is accommodated north of the ATF in the thrust system that formed along the distal part of the foreland alluvial fans. In the fault interpretation outlined in Figure 5d, the transfer of the convergence component of movement is achieved through a flat décollement up to the northernmost thrust.

\subsection{Apparent Shear Zone Along Jinsha Suture}

The second outstanding feature of the LOS surface velocity field is the broad east-west oriented shear zone that approximately follows the late Triassic Jinsha suture between the Qiangtang terrane to the south and the Songpan-Ganzi terrane to the north (e.g., Tapponnier et al., 2001; Yin \& Harrison, 2000) (Figure 3). The velocity map shows a distributed gradient of deformation centered on an axis near latitude $\sim 92^{\circ} \mathrm{N}$, extending along the Jinsha suture from the termination of the MF, which broke in 1997, in the east, to the Gozha Fault in the west (Figure 3). Active fault mapping from Landsat optical images does not show any continuous fault surface trace along the suture (Tapponnier \& Molnar, 1977), but geological maps and high-resolution images available in Google Earth clearly reveal the fabric of the crust in the suture zone, with WNW-ESE oriented, steeply dipping strata of a thick series of marine sediments referred to as the Songpan-Ganzi flysch complex in central Tibet (e.g., Yin \& Harrison, 2000). The propagation of a clear-cut strike slip fault may be difficult in such a highly anisotropic terrane, more prone to distributed deformation involving discontinuous fault segments interacting with the structure of the folded units. The LOS velocity change across the Jinsha suture is $\sim 3-4 \mathrm{~mm} / \mathrm{yr}$ with the southern side moving toward the satellite compared to the northern side (Figure 4). This signal does not have the characteristics of a velocity field caused by a thrust fault as the uplift would be concentrated at the tip of the creeping ramp and would die off away from it. We therefore interpret the signal as a broad shear zone accommodating left-lateral movements between the Qiangtang and the Songpan-Ganzi blocks. The signal could also be associated with a transient process following the 1997 Manyi earthquake (Figure 4), although no time dependence has been detected in the data.

The data also reveal a steep LOS velocity change of $\sim 1-2 \mathrm{~mm} / \mathrm{yr}$ across the western end of the northern branch of the MF (Figure 3 and profile BB' in Figure 4), which may extend farther west of our study area along the northern boundary of the large permafrost basin (masked area in Figure 3, blue pixels in Figure S11). GPS data do not reveal any clear shortening across this potential structure, which may be interpreted as a secondary strike-slip fault of the MF system.

Finally, we observe a negative LOS velocity change of $\sim 1-2 \mathrm{~mm} / \mathrm{yr}, 0-50 \mathrm{~km}$ south of the ATF (Profile BB' in Figure 4), only visible in the eastern part of the study area (Figure 3). Here GPS data indicate $2-3 \mathrm{~mm} / \mathrm{yr}$ of shortening velocity, which may also suggest vertical movements associated with contraction in the north dipping thrusts of the eastern Kunlun and Qiman ranges (Figure 3).

\section{Kinematic Modeling}

\subsection{Comparison With GPS Data}

We first compare our surface velocity map with GPS data provided by He et al. (2013), which includes 17 campaign stations measured two to three times between 2009 and 2011, and with the regional data set provided 


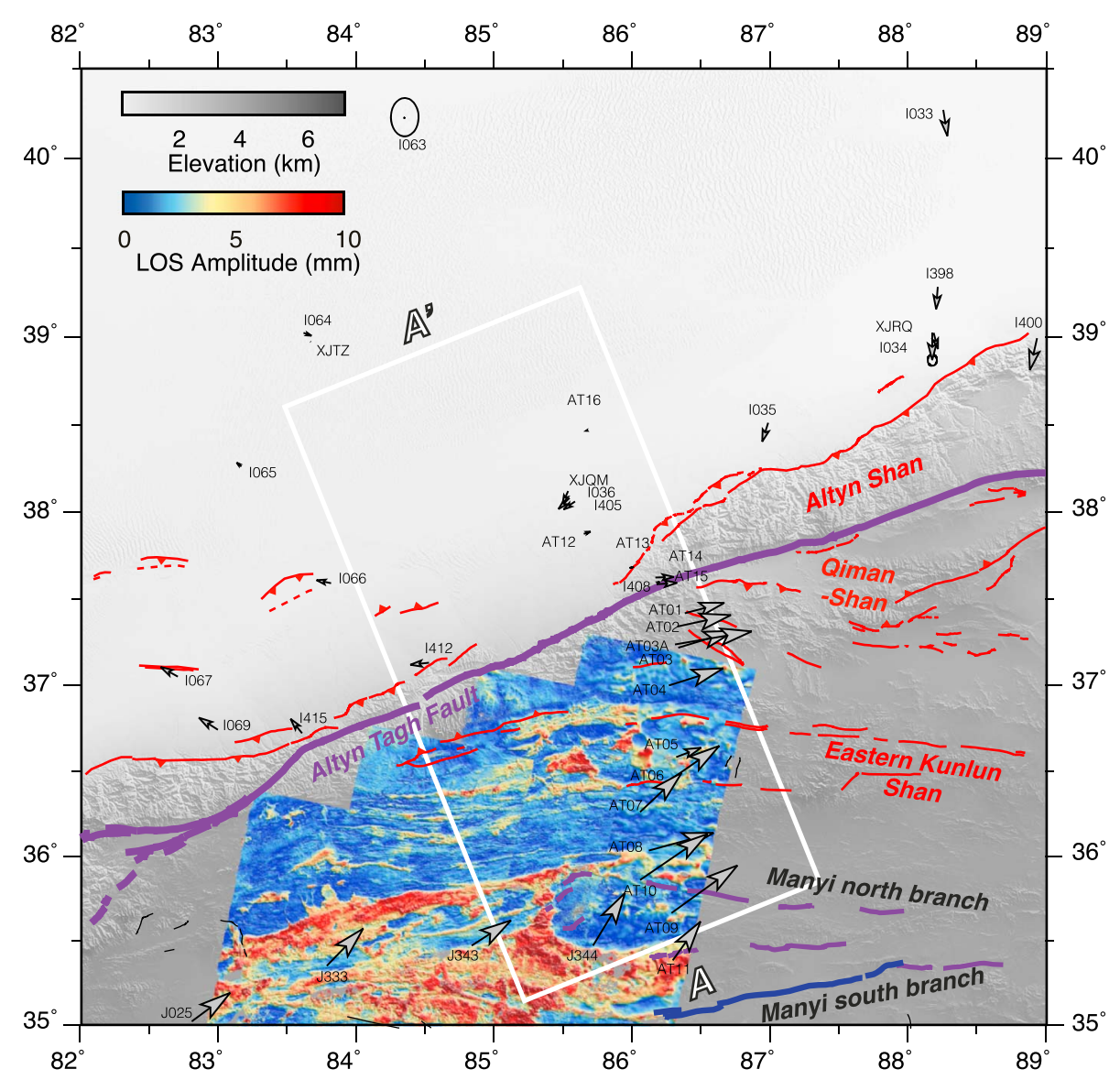

Figure 6. GPS velocities from Wang et al. (2017) and from He et al. (2013) referred with respect to the Tarim block and superimposed to the amplitude of the seasonal deformation due to the freeze and thaw cycles of the permafrost active layer derived in Daout et al. (2017). We use stations 1033, 1063, 1064, XJTZ, and 1065, located in the Tarim basin and far from any faults, to invert for the parameters of the Euler pole between the Tibetan and the Tarim blocks, which lies at latitude $45^{\circ} 49^{\prime}$ and longitude $-62^{\circ} 7^{\prime}$ with a clockwise angular velocity of $0.282 \mathrm{Ma}^{-1}$. Fault traces are as in Figure 1 . $\mathrm{AA}^{\prime}=200 \mathrm{~km}$ large and $300 \mathrm{~km}$ long profiles across the central segment of the ATF used in the model.

by Wang et al. (2017), which includes 23 continuous and campaign stations measured two to three times in our study area acquired between 1999 and 2014. In Figure 6, we superimpose the station locations on the amplitude of the ground seasonal deformation associated with the freeze-thaw cycle of the permafrost active layer (Daout et al., 2017). We observe that at least AT05, AT10, AT11, J343, and J344 stations are located within sedimentary basins that undergo strong seasonal deformation. The velocity estimated after two or three measurement campaigns must therefore be interpreted with caution at these stations.

In order to compare the GPS field of Wang et al. (2017) with the GPS solution of He et al. (2013), we rotate the International Terrestrial Reference Frame (ITRF) solution of Wang et al. (2017) with respect to the Tarim block, north of the ATF, and display the ATF-perpendicular and the ATF-parallel GPS velocity components for the two networks in Tables S1 and S2. On the eastern side of our study area, GPS stations 1035, XJRQ, 1034, 1400, and 1398 of Wang et al. (2017) (Table S2) clearly show the shortening component north of the Altyn Shan. GPS stations XJQM, 1036, and 1405 indicate a shortening and shearing relative to stations J333 and J343 of 2-5 mm/yr and $\sim 8 \mathrm{~mm} / \mathrm{yr}$, respectively. However, as discussed above, we consider the velocity of these two stations (J343 and J344) as unreliable due to seasonal deformation of the permafrost active layer (Figure 6). In comparison, the velocity gradient from He et al. (2013) (Table S1) shows a left-lateral far-field motion of $\sim 8-10 \mathrm{~mm} / \mathrm{yr}$ centered on the ATF and indicates no clear convergence between far-field stations in Tarim and Tibet (Figure 6). As seen in our velocity map, GPS stations AT14, AT15, AT01, AT02, AT03, AT03A, and AT04 seem to indicate a left-lateral or a thrust movement linked to the activity of the Qiman Shan. 


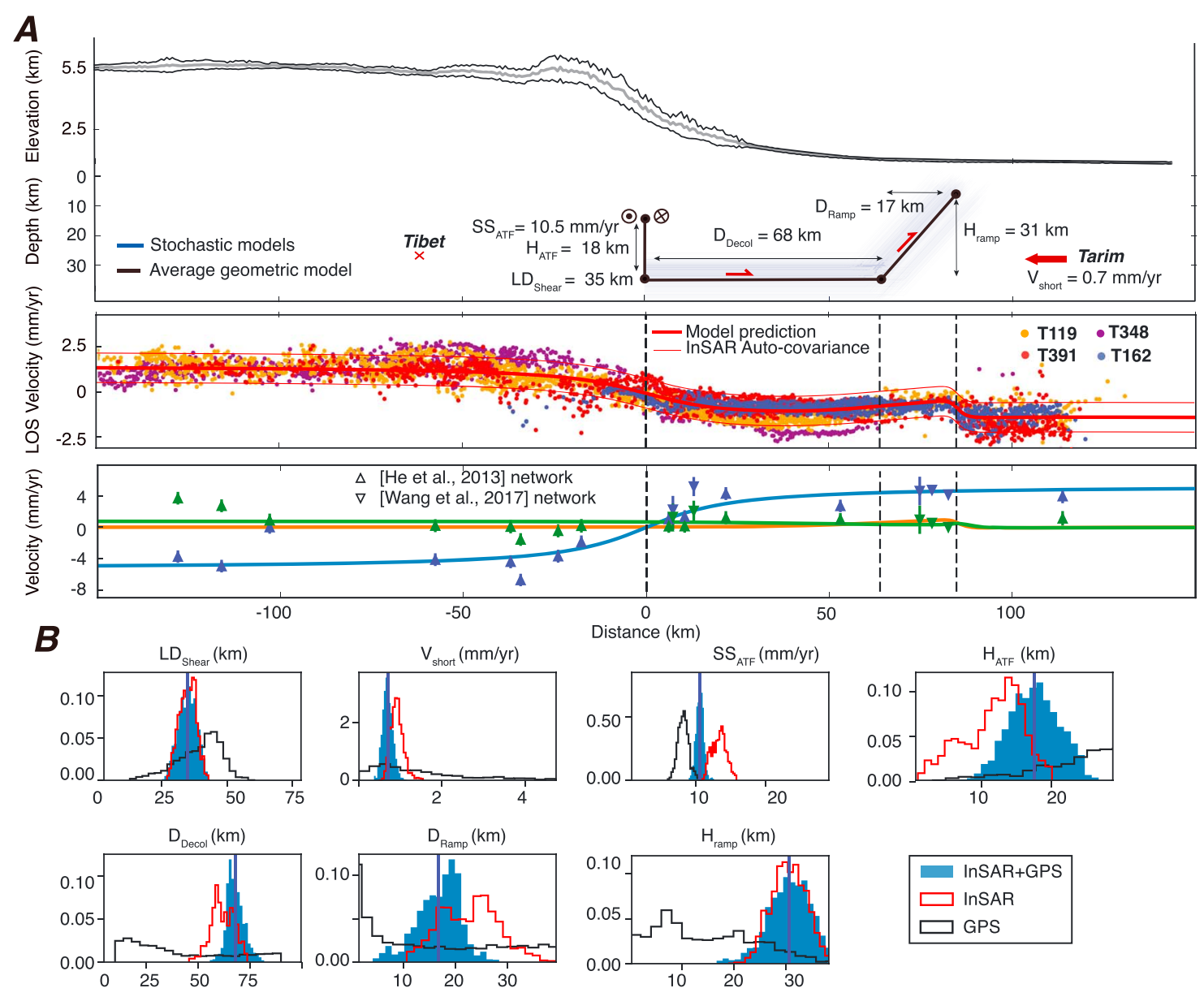

Figure 7. Inversion model and results for the profile perpendicular to the Altyn Tagh Fault (ATF) defined in Figure 6. (a) (top) Minimum, maximum, and average topography along the swath profile (back and gray lines), posterior models in agreement with the data (blue lines), and average posterior geometry (thick black lines) with associated slip rates. (middle) LOS velocities (cyan, blue, red, and orange points) along the swath profile (Figure 6). (bottom) Fault-perpendicular (green triangle and inverted triangle markers) and fault-parallel (blue triangle and inverted triangle markers) GPS velocities. Average model obtained and corresponding to fault-parallel, fault-perpendicular, and vertical velocities in blue, green, and orange lines, respectively, along profile. (b) Posterior marginal Probability Density Functions (PDFs) using GPS data only or InSAR data only (black and red unfilled histograms, respectively) or GPS+InSAR data (blue filled histograms), showing the gain of information from InSAR data. The boundaries of the histograms correspond to the uniform prior distributions.

\subsection{Two-Dimensional Profile Across the ATF}

We use the Bayesian inversion tool developed in Daout, Barbot, et al. (2016) to constrain the tectonic loading rate on the ATF system. We explore various fault geometries in agreement with the observed displacements along a $200 \mathrm{~km}$ wide and $300 \mathrm{~km}$ long profile covering the two GPS networks and four InSAR velocity maps (profile $A A^{\prime}$ in Figure 6). The model includes four dislocations embedded in an elastic half-space (Okada, 1985) (Figure 7). First, a deep-seated dislocation, with a tip depth, $L D_{\text {Shear }}$, below the ATF accommodates both far-field shortening $\left(V_{\text {short }}\right)$ and fault-parallel left-lateral horizontal movement $\left(S S_{\text {ATF }}\right)$ between Tarim and Tibet. Connecting to the tip of this dislocation, we define two other segments: a first segment extends the creep on the ATF upward by a distance, $H_{\text {ATF }}$, and a second segment is a flat structure (hereafter called décollement) that extends below the Tarim basin over a distance, $D_{\text {Decol }}$. The last dislocation is another ramp that connects the upper edge of the décollement to the down-dip end of the Cherchen Fault where the sharp step in velocity is observed at the base of the alluvial fans (Figure 5).

In order to limit the number of free parameters and derive a model kinematically consistent with the far-field movements, we impose the conservation of motion between the various fault segments (Daout, Barbot, et al., 2016). The horizontal projection of the dip-slip motion on each creeping ramp is equal to the shortening motion across the fault system. We also impose a slip along the creeping segment of the ATF equal to the far-field fault-parallel left-lateral horizontal movement, $S_{\text {ATF }}$. In addition to the far-field strike-slip and shortening motion on the half-infinite segment, we invert for its tip depth $\left(L D_{\text {Shear }}\right)$. For all other finite creeping 
segments, we explore their horizontal, $D$, and vertical, $H$, dimensions (Figure $7 a$ ). We assume a purely vertical ATF and only solve for its locking depth $\left(L D_{\text {Shear }}-H_{\text {ATF }}\right)$. We set no a priori constraint on all the parameters by assuming uniform prior probability distributions within wide parameter bounds. We also add an unknown azimuthal linear trend to InSAR data that ties far-field LOS velocities to GPS data.

We made some preliminary inversions to assess the level of complexity and partitioning of the movement between the ATF and the décollement-ramp to the north (Figures S19 and S20). Models allowing for both strike-slip and down-dip components on the ramp and décollement showed that the optimal strike-slip movement was close to 0 on these structures (Figure S20). The models also converge toward a solution with a flat (zero dip angle) décollement between the ATF and the northern ramp. We therefore impose horizontal décollement and a purely down-dip movement on the décollement and ramp in the subsequent models. The pure strike-slip and dip-slip partitioning is consistent with the absence of evidence of laterally displaced morphological structures along the Cherchen Fault in high-resolution images available in Google Earth. The geometry of the inverted model is consistent with the geometry inferred from tomography (Guilbaud et al., 2017; Wittlinger et al., 1998) and seismic reflection studies (Laborde, 2017) along this section of the ATF fault system (Figure 7a). The number of segments that we choose to model is necessary to fully account for the observed displacement field. For example, preliminary tests have revealed that a model without a shallow creeping segment on the ATF would limit the range of depths of the junction between the décollement and the deep-seated dislocation (Figure S19a). In addition, a model with a single thrust fault was not producing the sharp velocity gradient observed at the base of the foreland fans in the Tarim basin (Figure S19b).

We compare three solutions constrained by various combinations of the data sets. In the first model, the data vector only includes GPS velocities from He et al. (2013) and Wang et al. (2017) encompassing the InSAR swath profile (Figure 6). In the second model, the data vector includes the four LOS velocity maps only, while the third model combines the GPS and InSAR data.

The InSAR data vector is made of 4833 LOS InSAR velocity values spaced by $3 \mathrm{~km}$ from one another in north and east directions, a distance exceeding the correlation distance of the residual noise in the velocity maps (Figure S16). The GPS data vector includes the north and east components of 19 velocity vectors. The data covariance matrix contains only diagonal elements. The InSAR data points are assigned a variance equal to the square of the $0.8 \mathrm{~mm} / \mathrm{yr}$ uncertainty estimated from the discrepancy between colocated data points from adjacent tracks (Figure S15c). We can observe in data-profile (Figure 7b) that this uniform error encloses roughly the scattering of the LOS data points in 2-D. The error on the GPS velocity is based on the 1 sigma error published by the authors (He et al., 2013; Wang et al., 2017). The azimuthal and range-dependent LOS direction is defined for each InSAR data point.

A summary of the prior and posterior probabilities for the three models is provided in Table S3. The average posterior model and the comparison between observations and predictions is shown in profile in Figure 7a, as well as in map view in Figure S17, while the comparison between the prior and posterior Probability Density Functions (PDFs) for the three models is displayed in Figure 7b.

The fault models with GPS data alone and with InSAR data alone indicate an average ATF strike-slip rate of 8.1 [6.6-9.7] mm/yr and 13.3 [11.4-15.1] mm/yr, respectively (95\% interval confidences are given, Table S3). The décollement depth is at 39 [21-53] km and 35 [29-40] km, respectively. GPS data predict a shallow ATF locking depth of 8 [2-15] km, as well as a deep frontal ramp locked until 25 [4-44] km. On the contrary, InSAR data predict a locking depth on the ATF and on the frontal ramp of 23 [19-28] km and 4 [1-8] km, respectively. We observe that with GPS data alone, only the posterior PDFs of $S S_{\text {ATF }}$ and $L D_{\text {Shear }}$ resemble normal distributions. All other parameters are not well constrained with posterior PDFs close to uniform distributions (Figure 7b). In addition, GPS vectors do not clearly resolve the shortening motion across the fault system. On the contrary, posterior PDFs with InSAR data alone show well-constrained parameters with normal distributions.

The models constrained with both GPS and InSAR indicate a décollement depth of 35 [28-41] $\mathrm{km}$ and a creep of the ATF above the décollement junction over 17.6 [11.5-24.5] km (Table S3). The average locking depth of the ATF is thus over 17.4 [14.4-20.0] km with a slip rate of 10.5 [9.4-11.5] mm/yr. The model also constrains a high-angle frontal ramp dipping at $61[51-73]^{\circ}$ with a locking depth of 4 [1-8] km. The average shortening rate is 0.7 [0.5-1.0] mm/yr across the entire fault system. The relative movement of northern Tibet with respect to Tarim across the entire fault system strikes $62^{\circ} \mathrm{N},[61-63.5]^{\circ} \mathrm{E}$ at $10.5[9.4-11.5] \mathrm{mm} / \mathrm{yr}$. 

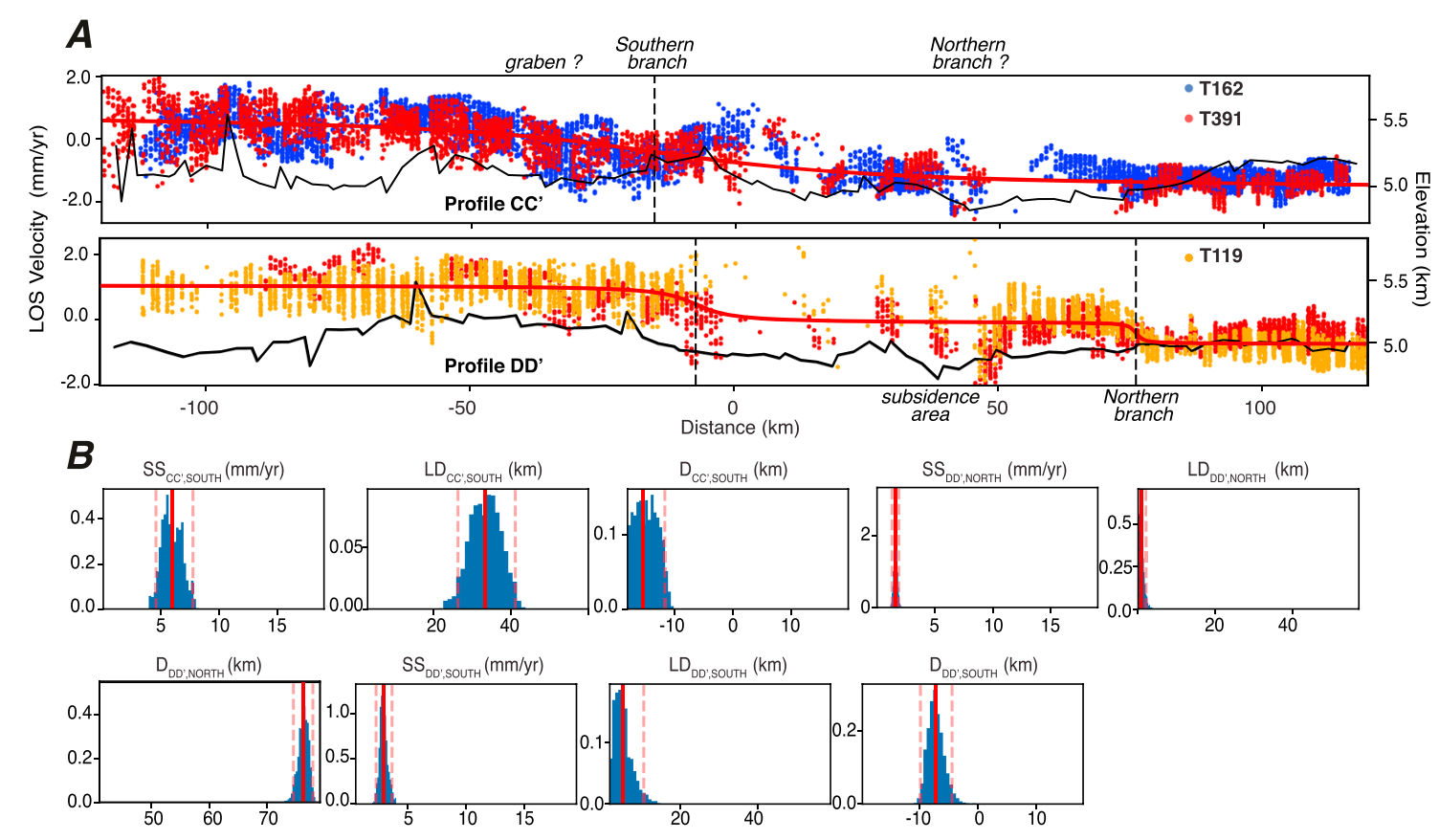

Figure 8. Inversion model and results for the two profiles $\mathrm{CC}^{\prime}$ and $\mathrm{DD}^{\prime}$ across the Jinsha suture defined in Figure 3. (a) Line-of-sight (LOS) velocities (cyan, blue, red, and orange points) along the four swath profiles with average model obtained in red and topography in black. (b) Posterior marginal PDF (blue histograms) with average posterior models (red vertical lines) and boundaries corresponding to the uniform prior distributions.

All estimated parameters have normal distributions centered on the average value (Figure 7b), and there is generally a good agreement between observations and predictions (Figure 7a). The RMS misfit between InSAR or GPS observations and the model predictions is of $0.314,0.368,0.371,0.396,0.05$, and $0.139 \mathrm{~mm} / \mathrm{yr}$, for the tracks 162, 391, 119, 38, GPS network of Wang et al. (2017), and GPS network of He et al. (2013), respectively.

\subsection{Two-Dimensional Profile Across the Jinsha Suture}

With the aim of giving first-order values of the shear rate responsible for the observed gradient across the Jinsha suture, we proceed with the same two-dimensional approach along the two profiles $C C^{\prime}$ and $D^{\prime}$ defined in Figure 3. The data vectors are made of the subsampled LOS velocity data from the two $240 \mathrm{~km}$ long and $60 \mathrm{~km}$ wide box profiles. All data points are associated with their LOS vectors. We approximate the distributed velocity gradient along the profile $C C^{\prime}$ by a gradient produced with a single vertical semi-infinite strike-slip dislocation. Such a representation is unrealistic for a broadly distributed shear zone and will lead to overestimated values for the model locking depth and strike-slip rates. For the profile $\mathrm{DD}^{\prime}$, we include two dislocations aiming at modeling the northern and southern branches of the MF. For both profiles, the modeled faults have a fixed strike of $\mathrm{N} 88^{\circ} \mathrm{E}$ and we search for the optimal values of locking depths, $L D$, strike-slip rates, SS, and horizontal shift of the fault location, $D$.

For the western profile $\mathrm{CC}^{\prime}$, the distributed gradient of deformation is reproduced by large locking depths,

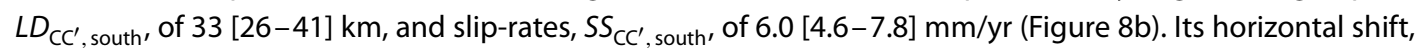
$D_{C C^{\prime} \text {, south, }}$ to the center of the profile is constrained at -15 [-20 to 12] km but is potentially biased by a graben identified in the southern part of the profile (Figures $8 \mathrm{a}$ and 3). The eastern profile, DD', is characterized by two localized gradients associated with the southern and northern branches of the MF (Figure 8a). A subsidence signal is also clearly visible at a distance of $40-50 \mathrm{~km}$ from the center of the profile, but it does not bias the model. Strike-slip rates converge to 3.0 [2.3-3.7] $\mathrm{mm} / \mathrm{yr}\left(\mathrm{SS}_{\mathrm{DD}^{\prime} \text {, south }}\right)$ and 1.7 [1.4-2.0] $\mathrm{mm} / \mathrm{yr}$ $\left(S S_{D D^{\prime}, \text { north }}\right)$ for the southern and northern branches, respectively. InSAR data indicate a very shallow locking

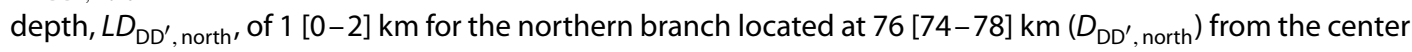
of the profile. For the southern branch, the locking depth, $L D_{\mathrm{DD}^{\prime}}$, south, is $5[2-11] \mathrm{km}$ with a horizontal position, $D_{\mathrm{DD}^{\prime} \text {, south, }}$ around the center of the profile at -7 [ -10 to 4$] \mathrm{km}$. All PDFs show well-constrained parameters with normal distributions that are much narrower than the prior distributions (Figure 8b). 


\section{Discussion and Conclusions}

\subsection{Systematic InSAR Processing in Tibet}

Due to the large trade-off between atmospheric delays, residual orbital ramps, and tectonic deformation, as well as noise related to hydrological and permafrost deformation, recovering high-coverage and high-accuracy InSAR velocity maps across the ATF is challenging. The approach presented here is based on a series of corrections applied to the wrapped phase that aim at improving the empirical estimations of the high-frequency component of the signal and enhancing the signal-to-noise ratio before unwrapping. We identified four main challenges for systematic InSAR processing in Tibet.

The first challenge is associated with the decorrelation of the phase, in particular across alluvial fans and sand dunes in the Tarim basin. Specific filtering and unwrapping procedures were dedicated to recover the far-field signal in the Tarim basin and Tibet, improving the recovery of the ATF displacement rate.

The second challenge concerns the separation of the effects of hydrology and permafrost seasonal changes in the high plateau and those related to the tectonic deformation. A specific focus on permafrost-related deformation (Daout et al., 2017) allows us to (1) correctly unwrap interferograms from north to south, in particular across sedimentary basins; (2) quantify the temporal behavior of the permafrost active layer; and (3) isolate bedrock pixels that are not affected by the seasonal signal for further tectonic analysis (note that this is also helpful to discard less reliable GPS velocities in the area).

The third difficulty is linked to the quadratic residual orbital ramps for interferograms longer than $300 \mathrm{~km}$. To improve the ramp estimation, we mask dune areas located at distances larger than $\sim 150 \mathrm{~km}$ north from the ATF, as well as sedimentary basins with more than $2.5 \mathrm{~mm} / \mathrm{yr}$ of seasonal movements. We optimize the ramp estimation by isolating bedrock pixels within the Tibetan Plateau and imposing a closure of the signal within the interferometric network. We notice a strong decrease of the velocity phase variability after this step that helps referring all interferograms to the same stable areas. Finally, we take advantage of the repetition of the signal in the overlapping areas to estimate residual ramps and refer the final velocity map to a unique incidence angle.

The fourth and most difficult challenge is the variable radar phase delay in the stratified atmosphere that is enhanced by the $4 \mathrm{~km}$ topographic step between the Tarim basin and the Tibetan Plateau. The high degree of correlation of the topography with the expected tectonic signal across the northern edge of Tibet, combined with the irregular temporal sampling of the Envisat data set, makes the empirical estimation of the atmospheric phase delay in interferograms inappropriate for the region. We choose to correct the interferograms using an estimation of the delay at each acquisition date based on the global atmospheric model ERA-I parameters (Doin et al., 2009). In addition, we propose a novel method to estimate uncertainties for the model predictions of the delays based on their temporal variability. We use these derived uncertainties to weight the time series inversion and estimate errors of $0.83 \mathrm{~mm} / \mathrm{yr}, 0.91 \mathrm{~mm} / \mathrm{yr}, 0.82 \mathrm{~mm} / \mathrm{yr}$, and $1.28 \mathrm{~mm} / \mathrm{yr}$ on the velocity gradient across the ATF due to the residual atmospheric delays for the tracks $162,391,119$, and 348 , respectively.

\subsection{Strain Partitioning in Northwest Tibet}

We have constructed the first LOS velocity map covering a $300 \times 500 \mathrm{~km}^{2}$ area from the Tarim basin to the central part of the Tibetan Plateau, continuous across high-relief areas and sedimentary basins (Figure 3). This map sheds new light on this remote region of Tibet where kinematics remains poorly known due to large geodetic and field data gaps. This picture of the 8 year average interseismic surface displacements reflects the deep-seated movement of the lower crust and the upper mantle, providing new insights into continental deformation. Surface displacements suggest that the strain is mostly localized along the ATF and the Jinsha suture zone (purple lines in Figure 3 that delimit accreted blocks). These lithospheric weaknesses control the partitioning of oblique convergence between Tibet and Tarim blocks into complex deformations in the detached, thickened, overlying upper crust (Avouac \& Tapponnier, 1993; Wittlinger et al., 1998).

A new observation is the sharp gradient of deformation within the northern foreland of the Altyn Shan. The deformation coincides with Plio-Quaternary structures revealed by seismic reflection data along the southern rim of the Tarim basin (Coudroy et al., 2009; Laborde, 2017; Wittlinger et al., 1998). The structures are interpreted as thrust faults affecting the Proterozoic basement and possibly the overlying sedimentary series. The faults have no clear surface expression except across the large alluvial fan of the Moleqie He (Figure 5c) 
where two branches dipping in opposite directions form a pop-up structure identified as the Tanan structure by Laborde (2017). The InSAR surface velocity map shows $\sim 1 \mathrm{~mm} / \mathrm{yr}$ of vertical movement across the faults.

A simple two-dimensional kinematic fault model constrained by InSAR and GPS data shows that the oblique movement between northern Tibet and the Tarim block is partitioned between left-lateral slip at a rate of $10.5 \mathrm{~mm} / \mathrm{yr}$ (see Table S3 for confidence intervals) on the ATF and pure convergence at a rate of $0.7 \mathrm{~mm} / \mathrm{yr}$ on a flat-ramp structure developed under the foreland fans along the southern rim of the Tarim block. The Bayesian model used in this study (Daout, Barbot, et al., 2016) imposes the conservation of motion between connected structures at depth, thus reducing the number of free parameters and imposing constraints on the range of possible models consistent with the observations. A direct consequence of this constraint is the strong anticorrelation observed between the the far-field shortening $\left(V_{\text {short }}\right)$ and the dip of the ramp, which is defined by model parameters $H$ and $D$ (Figures 7 and S18). An increase (decrease) in $V_{\text {short }}$ must be balanced by a decrease (increase) in the ramp dip angle to fit the observed uplift in southern Tarim. The same argument holds for the anticorrelation between $V_{\text {short }}$ and the depth of the décollement $\left(L D_{\text {shear }}\right.$ Figure 7$)$ because $L D_{\text {Shear }}$ also defines the depth of the base of the ramp and influences its dip angle and is therefore constrained by the observed uplift in the InSAR data. Because of the ENE orientation of the ATF system with respect to the observing geometry of InSAR from a descending satellite orbit, the left-lateral slip (SS $S_{\text {ATF }}$ ) and the perpendicular convergence $\left(V_{\text {short }}\right)$ across the structures result in opposite changes in LOS velocity. Consequently, these two parameters are correlated in the chain of solutions (Figure S18). However, the effect of this trade-off is largely limited by constraint on $V_{\text {short }}$ brought by the observed uplift north of the ATF and the conservation of motion. Note also that a model with only a single dipping half-infinite dislocation aiming to model thrusting deformation would uplift the entire Tibetan Plateau in contrast to a décollement-ramp structure that localizes the uplift on the ramp. Our conservation of motion assumption can therefore provide models that are in agreement with observations from structural geology (e.g., flower structures and décollement-ramp systems) limiting also the number of free parameters.

It is important to note that part of the total deformation produced by a thrust system may also take place within blocks through the formation of folds or secondary faulting such as back thrusts. For instance, the differential vertical velocity induced by the change of dip angle between the décollement and the frontal ramp needs to be accommodated during the seismic cycle by folding or back-thrust faulting in the hanging wall (Daout, Barbot, et al., 2016). Such structures may be locked during the interseismic period covered by the InSAR data and only activated when earthquakes break the main thrust as part of the coseismic deformation. As another possibility, the internal deformation of the hanging wall may occur during slow interseismic sliding events or during postseismic transient deformation as proposed by Copley (2014) and Copley and Jolivet (2016) for the Tabas-e-Golshan and Shahdad thrust systems, respectively, in Iran. Measuring such aseismic slip phenomena and understanding the kinematics of such fault-bend-fault structures is important to fully quantify the fault system seismic potential and integrate the role of internal and transient deformations. Here the fault model does not include such secondary structures in the hanging wall of the frontal ramp. The reason for this is the absence of signal associated with secondary structures during the observation period of the InSAR data, beside the small velocity change observed on the small back thrust on the Moleqie He fan (Figures $5 \mathrm{c}$ and $5 \mathrm{~d}$ ).

The two-dimensional model has the advantage of reducing the number of free parameters to a minimum yet reproducing well the observations (Figures 7 and S17). However, the velocity field highlights the three-dimensional complexity of the study area due to the branching of the Altyn or Qiman Shan thrusts or the interaction with the MF system. These faults are trending obliquely to the ATF, and a three-dimensional model would be required in order to take into account their contributions.

Our study emphasizes the complementarity of GPS and InSAR data in studying the thrust and strike-slip fault system along the northern edge of Tibet. InSAR data constrain the localization of the deformation and the geometry of the décollement-ramp system. Fault models estimated from InSAR data alone show well-constrained parameters with normal model ensemble distributions. However, constraining a model using data from a single LOS component results in trade-offs between slip rates and the long-wavelength residual signal. Conversely, using only the GPS data does not help constraining the geometry of the décollement-ramp structure resulting in broad posterior PDFs (Figure 7b). However, GPS data help to constrain the far-field shortening $\left(V_{\text {Short }}\right)$ and strike-slip motion $\left(S S_{A T F}\right)$. InSAR and GPS data together thus set the fault geometry and far-field rates. For instance, joint GPS-InSAR data models compensate lower shortening 
motion (Figure 7b) by converging to a higher dip angle of the ramp to be in agreement with the sharp InSAR signal observed in the Tarim ( $D_{\text {Ramp }}$ is higher for models with InSAR alone than for models with InSAR and GPS data together). However, reported GPS uncertainties are usually very small (less than $0.5 \mathrm{~mm} / \mathrm{yr}$ ) reflecting the formal error from the processing. Three simple models made of one single strike-slip half-infinite dislocation with locking depths fixed at 10, 20, or $30 \mathrm{~km}$ depths (Figure S21) show that GPS data uncertainties do not reflect the spread of GPS data, as all three models equally fit these GPS data. The reported uncertainties on GPS velocities seem to not include other systematic sources of errors, which may cause the scattering of the data points. More realistic errors should account for monument stability and aliased seasonal signal in campaign measurements.

The $\sim 1 \mathrm{~cm} / \mathrm{yr}$ strike-slip velocity derived from the model for this section of the ATF is consistent with present-day rates estimated using campaign GPS data on the same section (Elliott et al., 2008; He et al., 2013) and adjacent section(Wallace et al., 2004) of the fault, and within error bars, although lower than the mean value of the long-term rates estimated from the offset geological markers (e.g., Cowgill, 2007, 2009; Gold et al., 2009; Mériaux et al., 2004, 2005, 2012). The discrepancy between the decadal geodetic slip rate and some geological rate estimates may highlight the unsteady nature of the deformation around complex fault systems over periods of time of 10-100 kyr (e.g., Peltzer et al., 2001).

The LOS velocity field over NW Tibet highlights a wide active shear zone along the Jinsha suture zone as well as local concentration of shear on smaller faults in the Manyi fault system. The deformation pattern is not compatible with south directed thrusting in the Tianshuihai thrust belt (e.g., Cowgill et al., 2003) but might be the expression of the left-lateral shear between the Qiantang and the Songpan-Ganzi blocks along the weak lithospheric suture zone. A simple kinematic model composed of vertical semi-infinite strike-slip dislocations allows us to estimate approximate slip rates on these structures. However, the absence of a clear surface fault trace along the Jinsha suture and the inadequacy of such a model to represent the broad deformation signal leads to large uncertainties in the parameter estimates. Such uncertainties are exacerbated by the lack of GPS data and the large data gaps in the LOS data across the permafrost basins. Our results show that the Kunlun-MF system, which cuts across Tibet all the way to the Lungmen Shan and is characterized by Holocene and present-day slip rates of $\sim 11 \mathrm{~mm} / \mathrm{yr}$ (Garthwaite et al., 2013; Van Der Woerd et al., 2002), seems to extend westward along multiple secondary structures in the central part of the Tibetan Plateau, including north dipping thrusting along the eastern Kunlun Shan and left-lateral shear along the two branches of the MF. The modeled $4-8 \mathrm{~mm} / \mathrm{yr}$ of strike-slip motion in central Tibet is localized below the western termination of the MF system in the eastern part of our study area. Farther west in the plateau, the two branches of the MF system likely connect within a broad shear zone following the geological fabric of the Jinsha suture. This partitioned deformation shows that instead of moving to the NE as a single block to absorb the $\sim 2 \mathrm{~cm} / \mathrm{yr}$ of NS shortening between central Tibet and the Tarim basin (Wang et al., 2017), the region is deforming and part of the deformation produced by the extrusion process appears to be taking place along the Jinsha suture zone. However, the absence of a clear morphological fault trace indicates that deformation there is not localized in a narrow fault zone as observed along the ATF, which sharply offsets the upper Paleozoic granitoid of the Kunlun by $\sim 500$ km (Chengfa et al., 1986; Peltzer \& Tapponnier, 1988; Yin \& Harrison, 2000).

Our observations lead us to discard the hypothesis that the central part of the plateau deforms as a fluid in response to an undergoing gravitational collapse (England \& Houseman, 1989; England \& McKenzie, 1983; England \& Molnar, 1997a, 1997b). Instead, the oblique convergence between the Himalaya and the Tarim block seems to result from stresses that are large enough to initiate a long strike-slip fault as the ATF or reactivate lithospheric weakness zones such as the Jinsha suture. Slower-slipping shallow thrusts are locked during the interseismic period and root to low-angle and intracrustal structures that accumulate strain and connect to lithospheric boundaries such as the Jinsha suture or the ATF. The observed complex surface expression of the Tibetan fault system most likely reflects complementary facets of the deformation process. Such processes occur along major deep-seated structures that partition plate convergence toward the surface and govern the regional continental tectonic (Daout, Jolivet, et al., 2016; Tapponnier et al., 2001). A more complete description of the current tectonics of Tibet will be possible when decadal time series of radar data become available on both descending and ascending satellite tracks, improving our ability to separate EW and vertical movements of the surface. The European Space Agency Sentinel-1 missions and future NASA-ISRO Synthetic Aperture Radar (NISAR) mission will build the necessary archive for this endeavor. 


\section{Acknowledgments}

The SAR data set was provided by the European Space Agency (ESA) in the framework of the Dragon 3 program (projects ID 10686). The NSBAS development was funded through the CNES TOSCA program (SAR ready and TeraSAR Tibet projects). S. D.'s work is supported through the Young Scientist Dragon 3, the French Appel à projet Grenoble Innovation Recherche (AGIR) fellowship, and the CNRS Mastodons computing facilities. H. S. and, since recently, S. D., are supported by an Emmy-Noether grant of the German Research Foundation DFG. We are grateful to Amandine Laborde, Laurie Barrier, Martine Simoes, and Jerome Van-Der-Woerd for sharing their results ahead of publication as well as fruitful discussions about the tectonic setting of the area. We thank Juliet Biggs, Romain Jolivet, and an anonymous reviewer for their constructive criticisms that have significantly improved the manuscript. We also thank Benedetta Dini for the English proofreading of the manuscript. The 2-D modeling software (Flower2d) and the InSAR processing tool used to compute covariance (Kite; Isken et al., 2017; Heimann et al., 2017) are available on Github: https://github.com/simondaout/Flower2d, https://github.com/pyrocko/kite. Postprocessing and figures have been realized with the GMT software (Wessel \& Smith, 1991).

\section{References}

Amelung, F., Galloway, D. L., Bell, J. W., Zebker, H. A., \& Laczniak, R. J. (1999). Sensing the ups and downs of Las Vegas: InSAR reveals structural control of land subsidence and aquifer-system deformation. Geology, 27(6), 483-486.

Avouac, J.-P., \& Tapponnier, P. (1993). Kinematic model of active deformation in central Asia. Geophysical Research Letters, $20,895-898$.

Bawden, G. W., Thatcher, W., Stein, R. S., Hudnut, K. W., \& Peltzer, G. (2001). Tectonic contraction across Los Angeles after removal of groundwater pumping effects. Nature, 412, 812-815.

Béjar-Pizarro, M., Socquet, A., Armijo, R., Carrizo, D., Genrich, J., \& Simons, M. (2013). Andean structural control on interseismic coupling in the north Chile subduction zone. Nature Geoscience, 6(6), 462-467.

Bekaert, D., Hooper, A., \& Wright, T. (2015). A spatially variable power law tropospheric correction technique for InSAR data. Journal of Geophysical Research: Solid Earth, 120, 1345-1356. https://doi.org/10.1002/2014JB011558

Bell, M., Elliott, J., \& Parsons, B. (2011). Interseismic strain accumulation across the Manyi fault (Tibet) prior to the $1997 M_{w} 7.6$ earthquake. Geophysical Research Letters, 38, L24302. https://doi.org/10.1029/2011GL049762

Bendick, R., Bilham, R., Freymueller, J., Larson, K., \& Yin, G. (2000). Geodetic evidence for a low slip rate in the Altyn Tagh fault system. Nature, 404(6773), 69-72.

Biggs, J., Wright, T., Lu, Z., \& Parsons, B. (2007). Multi-interferogram method for measuring interseismic deformation: Denali fault, Alaska. Geophysical Journal International, 170(3), 1165-1179.

Bürgmann, R., Rosen, P. A., \& Fielding, E. J. (2000). Synthetic aperture radar interferometry to measure Earth's surface topography and its deformation. Annual Review of Earth and Planetary Sciences, 28(1), 169-209.

Cavalié, O., Doin, M.-P., Lasserre, C., \& Briole, P. (2007). Ground motion measurement in the Lake Mead area, Nevada, by differential synthetic aperture radar interferometry time series analysis: Probing the lithosphere rheological structure. Journal of Geophysical Research, 112, B03403. https://doi.org/10.1029/2006JB004344

Cavalié, O., Lasserre, C., Doin, M.-P., Peltzer, G., Sun, J., Xu, X., et al. (2008). Measurement of interseismic strain across the Haiyuan fault (Gansu, China), by InSAR. Earth and Planetary Science Letters, 275, 246-257.

Cervelli, P., Segall, P., Amelung, F., Garbeil, H., Meertens, C., Owen, S., et al. (2002). The 12 September 1999 upper east rift zone dike intrusion at Kilauea Volcano, Hawaii. Journal of Geophysical Research, 107(B7), 2150. https://doi.org/10.1029/2001JB000602

Chang, L., \& Hanssen, R. (2015). Detection of permafrost sensitivity of the Qinghai-Tibet railway using satellite radar interferometry. International Journal of Remote Sensing, 36(3), 691-700.

Cheng, F., Jolivet, M., Fu, S., Zhang, C., Zhang, Q., \& Guo, Z. (2016). Large-scale displacement along the Altyn Tagh fault (north Tibet) since its Eocene initiation: Insight from detrital zircon U-Pb geochronology and subsurface data. Tectonophysics, 677, $261-279$.

Chengfa, C., Nansheng, C., Coward, M., Wanming, D., Dewey, J., Gansser, A., et al. (1986). Preliminary conclusions of the Royal Society and Academia Sinica 1985 geotraverse of Tibet. Nature, 323(6088), 501-507.

Clark, M. K., \& Royden, L. H. (2000). Topographic ooze: Building the eastern margin of Tibet by lower crustal flow. Geology, $28(8), 703-706$.

Cook, K. L., \& Royden, L. H. (2008). The role of crustal strength variations in shaping orogenic plateaus, with application to Tibet. Journal of Geophysical Research, 113, B08407. https://doi.org/10.1029/2007JB005457

Copley, A. (2014). Postseismic afterslip 30 years after the 1978 Tabas-e-Golshan (Iran) earthquake: Observations and implications for the geological evolution of thrust belts. Geophysical Journal International, 197(2), 665-679.

Copley, A., \& Jolivet, R. (2016). Fault rheology in an aseismic fold-thrust belt (Shahdad, eastern Iran). Journal of Geophysical Research: Solid Earth, 121, 412-431. https://doi.org/10.1002/2015JB012431

Coudroy, T., Li, H., van der Woerd, J., Barrier, L., Simoes, M., Tapponnier, P., et al. (2009). Deformation and propagation of the western Kunlun foreland into the Tarim basin (Xinjiang, China). AGU Fall Meeting Abstracts, 1, 0771.

Cowgill, E. (2007). Impact of riser reconstructions on estimation of secular variation in rates of strike-slip faulting: Revisiting the Cherchen River site along the Altyn Tagh fault, NW China. Earth and Planetary Science Letters, 254(3), 239-255.

Cowgill, E., Gold, R. D., Xuanhuan, C., Xia-Feng, W., Arrowsmith, J. R., \& Southon, J. (2009). Low quaternary slip rate reconciles geodetic and geologic rates along the Altyn Tagh fault, northern Tibet. Geology, 37, 647-650.

Cowgill, E., Yin, A., Harrison, T. M., \& Xiao-Feng, W. (2003). Reconstruction of the Altyn Tagh fault based on U-Pb geochronology: Role of back thrusts, mantle sutures, and heterogeneous crustal strength in forming the Tibetan Plateau. Journal of Geophysical Research, 108(B7), 2346. https://doi.org/10.1029/2002JB002080

Daout, S., Barbot, S., Peltzer, G., Doin, M.-P., Liu, Z., \& Jolivet, R. (2016). Constraining the kinematics of metropolitan Los Angeles faults with a slip-partitioning model. Geophysical Research Letters, 43, 11,192-11,201. https://doi.org/10.1002/2016GL071061

Daout, S., Doin, M.-P., Peltzer, G., Socquet, A., \& Lasserre, C. (2017). Large scale InSAR monitoring of permafrost freeze-thaw cycles on the Tibetan Plateau. Geophysical Research Letters, 44, 901-909. https://doi.org/10.1002/2016GL070781

Daout, S., Jolivet, R., Lasserre, C., Doin, M.-P., Barbot, S., Tapponnier, P., et al. (2016). Along-strike variations of the partitioning of convergence across the Haiyuan fault system detected by InSAR. Geophysical Journal International, 205(1), 536-547.

Dee, D., Uppala, S., Simmons, A., Berrisford, P., Poli, P., Kobayashi, S., et al. (2011). The ERA-Interim reanalysis: Configuration and performance of the data assimilation system. Quarterly Journal of the Royal Meteorological Society, 137(656), 553-597.

Delacourt, C., Briole, P., \& Achache, J. (1998). Tropospheric corrections of SAR interferograms with strong topography. Application to Etna. Geophysical Research Letters, 25(15), 2849-2852.

DeVries, P. M., \& Meade, B. J. (2013). Earthquake cycle deformation in the Tibetan Plateau with a weak mid-crustal layer. Journal of Geophysical Research: Solid Earth, 118, 3101-3111. https://doi.org/10.1002/jgrb.50209

DeVries, P. M., \& Meade, B. J. (2016). Kinematically consistent models of viscoelastic stress evolution. Geophysical Research Letters, 43, 4205-4214. https://doi.org/10.1002/2016GL068375

Doin, M.-P., Lasserre, C., Peltzer, G., Cavalié, O., \& Doubre, C. (2009). Corrections of stratified tropospheric delays in SAR interferometry: Validation with global atmospheric models. Journal of Applied Geophysics, 69, 35-50.

Doin, M.-P., Lodge, F., Guillaso, S., Jolvet, R., Lasserre, C., Ducret, G., et al. (2011). Presentation of the small baseline NSBAS processing chain on a case example: The Etna deformation monitoring from 2003 to 2010 using Envisat data. In Proceedings of Fringe 2011. Frascati, Italy.

Doin, M.-P., Twardzik, C., Ducret, G., Lasserre, C., Guillaso, S., \& Jianbao, S. (2015). InSAR measurement of the deformation around Siling Co Lake: Inferences on the lower crust viscosity in central Tibet. Journal of Geophysical Research: Solid Earth, 120, 5290-5310. https://doi.org/10.1002/2014JB011768

Ducret, G., Doin, M.-P., Grandin, R., Lasserre, C., \& Guillaso, S. (2014). DEM corrections before unwrapping in a small baseline strategy for InSAR time series analysis. Geoscience and Remote Sensing Letters, IEEE, 11, 696-700.

Elliott, J. R., Biggs, J., Parsons, B., \& Wright, T. J. (2008). InSAR slip rate determination on the Altyn Tagh fault, northern Tibet, in the presence of topographically correlated atmospheric delays. Journal of Geophysical Research, 35, L12309. https://doi.org/10.1029/2008GL033659 
England, P., \& Houseman, G. (1989). Extension during continental convergence, with application to the Tibetan Plateau. Journal of Geophysical Research, 94(B12), 17,561-17,579.

England, P., \& McKenzie, D. (1983). Correction to: A thin viscous sheet model for continental deformation. Geophysical Journal International, $73(2), 523-532$.

England, P., \& Molnar, P. (1997a). Active deformation of Asia: From kinematics to dynamics. Science, 278, 647-650.

England, P., \& Molnar, P. (1997b). The field of crustal velocity in Asia calculated from Quaternary rates of slip on faults. Journal of Geophysical Research, 130, 551-582.

Farr, T. G., \& Kobrick, M. (2000). Shuttle Radar Topography Mission produces a wealth of data. Eos, Transactions American Geophysical Union, $81(48), 583-585$.

Fattahi, H., \& Amelung, F. (2014). InSAR uncertainty due to orbital errors. Geophysical Journal International, 199(1), 549-560.

Fattahi, H., \& Amelung, F. (2015). InSAR bias and uncertainty due to the systematic and stochastic tropospheric delay. Journal of Geophysical Research: Solid Earth, 120, 8758-8773. https://doi.org/10.1002/2015JB012419

Fruneau, B., \& Sarti, F. (2000). Detection of ground subsidence in the city of Paris using radar interferometry: Isolation of deformation from atmospheric artifacts using correlation. Geophysical Research Letters, 27(24), 3981-3984.

Fruneau, B., Achache, J., \& Delacourt, C. (1996). Observation and modelling of the Saint-Etienne-de-Tinée landslide using SAR interferometry. Tectonophysics, 265(3-4), 181-190.

Funning, G. J., Parsons, B., \& Wright, T. J. (2007). Fault slip in the 1997 Manyi, Tibet earthquake from linear elastic modelling of InSAR displacements. Geophysical Journal International, 169(3), 988-1008.

Garthwaite, M. C., Wang, H., \& Wright, T. J. (2013). Broadscale interseismic deformation and fault slip rates in the central Tibetan Plateau observed using InSAR. Journal of Geophysical Research: Solid Earth, 118, 5071-5083. https://doi.org/10.1002/jgrb.50348

Gaudemer, Y., Tapponier, P., Meyer, B., Peltzer, G., Shunmin, G., Zhitai, C., et al. (1995). Partionning of crustal slip between linked, active faults in the eastern Qilian Shan, and evidence for a major seimic gap, the "Tianzhu gap", on the western Haiyuanfault, Gansu (China). Geophysical Journal International, 120, 599-645.

Ge, W.-P., Molnar, P., Shen, Z.-K., \& Li, Q. (2015). Present-day crustal thinning in the southern and northern Tibetan Plateau revealed by GPS measurements. Geophysical Research Letters, 42, 5227-5235. https://doi.org/10.1002/2015GL064347

Gold, R. D., Cowgill, E., Arrowsmith, J. R., Gosse, J., Chen, X., \& Wang, X.-F. (2009). Riser diachroneity, lateral erosion, and uncertainty in rates of strike-slip faulting: A case study from Tuzidun along the Altyn Tagh fault, NW China. Journal of Geophysical Research, 114, B04401. https://doi.org/10.1029/2008JB005913

Grandin, R., Socquet, A., Binet, R., Klinger, Y., Jacques, E., de Chabalier, J.-B., et al. (2009). September 2005 Manda Hararo-Dabbahu rifting event, Afar (Ethiopia): Constraints provided by geodetic data. Journal of Geophysical Research, 114, B04401. https://doi.org/10.1029/2008JB005913

Grandin, R., Doin, M.-P., Bollinger, L., Pinel-Puysségur, B., Ducret, G., Jolivet, R., et al. (2012). Long-term growth of the Himalaya inferred from interseismic InSAR measurement. Geology, 40(12), 1059-1062.

Guilbaud, C., Simoes, M., Barrier, L., Laborde, A., Van der Woerd, J., Li, H., et al. (2017). Kinematics of active deformation across the western Kunlun mountain range (Xinjiang, China) and potential seismic hazards within the southern Tarim basin. Journal of Geophysical Research: Solid Earth, 122, 10,398-10,426. https://doi.org/10.1002/2017JB014069

Guillaso, S., Reigber, A., Ferro-Famil, L., \& Pottier, E. (2006). Range resolution improvement of airborne SAR images. IEEE Geoscience and Remote Sensing Letters, 3(1), 135-139.

Hanssen, R. F. (2001). Radar interferometry: Data interpretation and error analysis (Vol. 2). Netherlands: Springer Science \& Business Media.

Hanssen, R. F., Weckwerth, T. M., Zebker, H. A., \& Klees, R. (1999). High-resolution water vapor mapping from interferometric radar measurements. Science, 283(5406), 1297-1299.

He, J., Vernant, P., Chéry, J., Wang, W., Lu, S., Ku, W., et al. (2013). Nailing down the slip rate of the Altyn Tagh fault. Geophysical Research Letters, 40, 5382-5386. https://doi.org/10.1002/2013GL05749

Heimann, S., Kriegerowski, M., Isken, M., Cesca, S., Daout, S., Grigoli, F., et al. (2017). Pyrocko-An open-source seismology toolbox and library. GFZ Data Services. https://doi.org/10.5880/GFZ.2.1.2017.001

Hilley, G. E., Bürgmann, R., Ferretti, A., Novali, F., \& Rocca, F. (2004). Dynamics of slow-moving landslides from permanent scatterer analysis. Science, 304(5679), 1952-1955.

Hooper, A., Bekaert, D., Spaans, K., \& Arkan, M. (2012). Recent advances in SAR interferometry time series analysis for measuring crustal deformation. Tectonophysics, 514, 1-13.

Huang, M.-H., Bürgmann, R., \& Freed, A. M. (2014). Probing the lithospheric rheology across the eastern margin of the Tibetan Plateau. Earth and Planetary Science Letters, 396, 88-96.

Isken, M., Sudhaus, H., Heimann, S., Steinberg, A., Daout, S., \& Vasyura-Bathke, H. (2017). Kite-Software for rapid earthquake source optimisation from InSAR surface displacement. GFZ Data Services. https://doi.org/10.5880/GFZ.2.1.2017.002

Jiang, X., Li, Z.-X., \& Li, H. (2013). Uplift of the west Kunlun range, northern Tibetan Plateau, dominated by brittle thickening of the upper crust. Geology, 41(4), 439-442.

Jolivet, M., Brunel, M., Seward, D., Xu, Z., Yang, J., Roger, F., et al. (2001). Mesozoic and Cenozoic tectonics of the northern edge of the Tibetan Plateau: Fission-track constraints. Tectonophysics, 343(1), 111-134.

Jolivet, R., Agram, P. S., Lin, N. Y., Simons, M., Doin, M.-P., Peltzer, G., et al. (2014). Improving InSAR geodesy using global atmospheric models. Journal of Geophysical Research: Solid Earth, 119, 2324-2341. https://doi.org/10.1002/2013JB010588

Jolivet, R., Cattin, R., Chamot-Rooke, N., Lasserre, C., \& Peltzer, G. (2008). Thin-plate modeling of interseismic deformation and asymmetry across the Altyn Tagh fault zone. Geophysical Research Letters, 35, L02309. https://doi.org/10.1029/2007GL031511

Jolivet, R., Grandin, R., Lasserre, C., Doin, M.-P., \& Peltzer, G. (2011). Systematic InSAR tropospheric phase delay corrections from global meteorological reanalysis data. Geophysical Research Letters, 38, L17311. https://doi.org/10.1029/2011GL048757

Jolivet, R., Lasserre, C., Doin, M.-P., Peltzer, G., Avouac, J.-P., Jianbao, S., et al. (2013). Spatio-temporal evolution of aseismic slip along the Haiyuan fault, China: Implications for fault frictional properties. Earth and Planetary Science Letters, 377-378, 23-33.

Laborde, A. (2017). Déformation Cénozoique du bassin du Tarim (Xinjiang, Chine) et impact sur son paysage morpho-sédimentaire actuel, Institut de Physique du Globe (Paris).

Lasserre, C., Cavalié, O., Peltzer, G., Socquet, A., Doin, M., Jianbao, S., et al. (2007). Interseismic strain across the Altyn Tagh and Haiyuan faults at the northern edge of the Tibetan Plateau, measured by space geodesy. Geophysical Research Abstracts CDROM, 9, 10102.

Lasserre, C., Gaudemer, Y., Tapponnier, P., Meriaux, A.-S., der Woerd, J. V., Daoyang, Y., et al. (2002). Fast late Pleistocene slip rate on the Leng Long Ling segment of the Haiyuan fault, Qinghai, China. Journal of Geophysical Research, 107(B11), 2276. https://doi.org/10.1029/2000JB000060 
Lauknes, T. R., Zebker, H., \& Larsen, Y. (2011). InSAR deformation time series using an $L_{1}$-norm small-baseline approach. Geoscience and Remote Sensing, IEEE Transactions on, 49(1), 536-546.

Leloup, P. H., Ricard, Y., Battaglia, J., \& Lacassin, R. (1999). Shear heating in continental strike-slip shear zones: Model and field examples. Geophysical Journal International, 136(1), 19-40.

Li, Z., Fielding, E. J., Cross, P., \& Muller, J.-P. (2006). Interferometric synthetic aperture radar atmospheric correction: GPS topography-dependent turbulence model. Journal of Geophysical Research, 111, B02404. https://doi.org/10.1029/2005JB003711

Li, Z., Xu, W., Feng, G., Hu, J., Wang, C., Ding, X., et al. (2012). Correcting atmospheric effects on InSAR with MERIS water vapour data and elevation-dependent interpolation model. Geophysical Journal International, 189(2), 898-910.

Liang, S., Gan, W., Shen, C., Xiao, G., Liu, J., Chen, W., et al. (2013). Three-dimensional velocity field of present-day crustal motion of the Tibetan Plateau derived from GPS measurements. Journal of Geophysical Research: Solid Earth, 118, 5722-5732. https://doi.org/10.1002/2013JB010503

Lin, Y.-n. N., Simons, M., Hetland, E. A., Muse, P., \& DiCaprio, C. (2010). A multiscale approach to estimating topographically correlated propagation delays in radar interferograms. Geochemistry, Geophysics, Geosystems, 11, Q09002. https://doi.org/10.1029/2010GC003228

Liu, L., Zhang, T., \& Wahr, J. (2010). InSAR measurements of surface deformation over permafrost on the North Slope of Alaska. Journal of Geophysical Research, 115, F03023. https://doi.org/10.1029/2009JF001547

López-Quiroz, P., Doin, M.-P., Tupin, F., Briole, P., \& Nicolas, J.-M. (2009). Time series analysis of Mexico City subsidence constrained by radar interferometry. Journal of Applied Geophysics, 69(1), 1-15.

Lu, R., Xu, X., He, D., Liu, B., Tan, X., \& Wang, X. (2016). Coseismic and blind fault of the 2015 Pishan $M_{w} 6.5$ earthquake: Implications for the sedimentary-tectonic framework of the western Kunlun mountains, northern Tibetan Plateau. Tectonics, 35, 956-964. https://doi.org/10.1002/2015TC004053

Manconi, A., \& Casu, F. (2012). Joint analysis of displacement time series retrieved from SAR phase and amplitude: Impact on the estimation of volcanic source parameters. Geophysical Research Letters, 39, L14301. https://doi.org/10.1029/2012GL052202

Matte, P., Tapponnier, P., Arnaud, N., Bourjot, L., Avouac, J., Vidal, P., et al. (1996). Tectonics of western Tibet, between the Tarim and the Indus. Earth and Planetary Science Letters, 142(3), 311-330.

Mériaux, A.-S., Ryerson, F., Tapponnier, P., Van der Woerd, J., Finkel, R., Xu, X., et al. (2004). Rapid slip along the central Altyn Tagh fault: Morphochronologic evidence from Cherchen He and Sulamu Tagh. Journal of Geophysical Research, 109, B06401. https://doi.org/10.1029/2003JB002558

Mériaux, A.-S., Tapponnier, P., Ryerson, F., Xiwei, X., King, G., Van der Woerd, J., et al. (2005). The Aksay segment of the northern Altyn Tagh fault: Tectonic geomorphology, landscape evolution, and Holocene slip rate. Journal of Geophysical Research, $110, \mathrm{~B} 04404$. https://doi.org/10.1029/2004JB003210

Mériaux, A.-S., Van Der Woerd, J., Tapponnier, P., Ryerson, F. J., Finkel, R. C., Lasserre, C., et al. (2012). The Pingding segment of the Altyn Tagh fault (91e): Holocene slip-rate determination from cosmogenic radionuclide dating of offset fluvial terraces. Journal of Geophysical Research, 117, B09406. https://doi.org/10.1029/2012JB009289

Meyer, B., Tapponnier, P., Bourjot, L., Metivier, F., Gaudemer, Y., Peltzer, G., et al. (1998). Crustal thickening in Gausu-Qinghai, lithospheric mantle subduction, and oblique, strike-slip controlled growth of the Tibet Plateau. Geophysical Journal International, 135, 1-47.

Molnar, P., \& Tapponnier, P. (1975). Cenozoic tectonics of Asia: Effects of a continental collision. Science, 189(4201), 419-426.

Okada, Y. (1985). Surface deformation to shear and tensile faults in a half-space. Bulletin of the Seismological Society of America, 75 , $1135-1154$.

Pathier, E., Fruneau, B., Deffontaines, B., Angelier, J., Chang, C.-P., Yu, S.-B., et al. (2003). Coseismic displacements of the footwall of the Chelungpu fault caused by the 1999, Taiwan, Chi-Chi earthquake from InSAR and GPS data. Earth and Planetary Science Letters, 212(1), 73-88.

Pedersen, R., \& Sigmundsson, F. (2006). Temporal development of the 1999 intrusive episode in the Eyjafjallajökull volcano, Iceland, derived from InSAR images. Bulletin of Volcanology, 68(4), 377-393.

Peltzer, G., Crampé, F., \& King, G. (1999). Evidence of nonlinear elasticity of the crust from the $M_{w} 7.6$ Manyi (Tibet) earthquake. Science, 286(5438), 272-276.

Peltzer, G., Crampé, F., Hensley, S., \& Rosen, P. (2001). Transient strain accumulation and fault interaction in the eastern California shear zone. Geology, 29(11), 975-978.

Peltzer, G., \& Saucier, F. (1996). Present-day kinematics of Asia derived from geologic fault rates. Journal of Geophysical Research, 101(B12), 27,943-27,956.

Peltzer, G., \& Tapponnier, P. (1988). Formation and evolution of strike-slip faults, rifts, and basins during the India-Asia collision: An experimental approach. Journal of Geophysical Research, 93, 15,085-15,117.

Peltzer, G., Tapponnier, P., \& Armijo, R. (1989). Magnitude of late quaternary left-lateral displacements along the north edge of Tibet. Science, 246(4935), 1285-1289.

Pinel, V., Hooper, A., la Cruz-Reyna, D., Reyes-Davila, G., \& Doin, M. (2008). Study of the deformation field of two active Mexican stratovolcanoes (Popocatepelt and Colima volcano) by time series of InSAR data. In H. Lacoste \& L. Ouwerhand (Eds.), Proceedings of FRINGE 2007. Frascati.

Pinel-Puyssegur, B., Michel, R., \& Avouac, J.-P. (2012). Multi-link InSAR time series: Enhancement of a wrapped interferometric database. IEEE Journal of Selected Topics in Applied Earth Observations and Remote Sensing, 5(3), 784-794.

Replumaz, A., \& Tapponnier, P. (2003). Reconstruction of the deformed collision zone between India and Asia by backward motion of lithospheric blocks. Journal of Geophysical Research, 108(B6), 2285. https://doi.org/10.1029/2001JB000661

Rosen, P. A., Hensley, S., Peltzer, G., \& Simons, M. (2004). Updated repeat orbit interferometry package released. Eos, Transactions American Geophysical Union, 85(5), 47-47.

Rousset, B., Jolivet, R., Simons, M., Lasserre, C., Riel, B., Milillo, P., et al. (2016). An aseismic slip transient on the north Anatolian fault. Geophysical Research Letters, 43, 3254-3262. https://doi.org/10.1002/2016GL068250

Royden, L. H., Burchfiel, B. C., King, R. W., Wang, E., Chen, Z., Shen, F., et al. (1997). Surface deformation and lower crustal flow in eastern Tibet. Science, 276(5313), 788-790.

Ryder, I., Bürgmann, R., \& Pollitz, F. (2011). Lower crustal relaxation beneath the Tibetan Plateau and Qaidam basin following the 2001 Kokoxili earthquake. Geophysical Journal International, 187(2), 613-630.

Ryder, I., Parsons, B., Wright, T. J., \& Funning, G. J. (2007). Post-seismic motion following the 1997 Manyi (Tibet) earthquake: InSAR observations and modelling. Geophysical Journal International, 169(3), 1009-1027.

Schlögel, R., Doubre, C., Malet, J.-P., \& Masson, F. (2015). Landslide deformation monitoring with ALOS/PALSAR imagery: A D-InSAR geomorphological interpretation method. Geomorphology, 231, 314-330. 
Shirzaei, M., \& Burgmann, R. (2012). Topography correlated atmospheric delay correction in radar interferometry using wavelet transforms. Geophysical Research Letters, 39, L01305. https://doi.org/10.1029/2011GL049971

Short, N., Brisco, B., Couture, N., Pollard, W., Murnaghan, K., \& Budkewitsch, P. (2011). A comparison of TerraSAR-X, RADARSAT-2 and ALOS-PALSAR interferometry for monitoring permafrost environments, case study from Herschel Island, Canada. Remote Sensing of Environment, 115(12), 3491-3506.

Strozzi, T., \& Wegmuller, U. (1999). Land subsidence in Mexico City mapped by ERS differential SAR interferometry. In Geoscience and Remote Sensing Symposium, 1999. IGARSS'99 Proceedings. IEEE 1999 International (Vol. 4, pp. 1940-1942). IEEE.

Strozzi, T., Ambrosi, C., \& Raetzo, H. (2013). Interpretation of aerial photographs and satellite SAR interferometry for the inventory of landslides. Remote Sensing, 5(5), 2554-2570.

Sudhaus, H., \& Jónsson, S. (2011). Source model for the 1997 Zirkuh earthquake $\left(M_{w}=7.2\right)$ in Iran derived from JERS and ERS InSAR observations. Geophysical Journal International, 185(2), 676-692.

Sun, J., Shen, Z.-K., Li, T., \& Chen, J. (2016). Thrust faulting and 3D ground deformation of the 3 July $2015 M_{w} 6.4$ Pishan, China earthquake from Sentinel-1A radar interferometry. Tectonophysics, 683, 77-85.

Tapponnier, P., \& Molnar, P. (1977). Active faulting and tectonics in China. Journal of Geophysical Research, 82(20), $2905-2927$.

Tapponnier, P., Peltzer, G., Le Dain, A., Armijo, R., \& Cobbold, P. (1982). Propagating extrusion tectonics in Asia: New insights from simple experiments with plasticine. Geology, 10(12), 611-616.

Tapponnier, P., Zhiqin, X., Roger, F., Meyer, B., Arnaud, N., Wittlinger, G., et al. (2001). Oblique stepwise rise and growth of the Tibet Plateau. Science, 294(5547), 1671-1677.

Taylor, M., \& Peltzer, G. (2006). Current slip rates on conjugate strike-slip faults in central Tibet using synthetic aperture radar interferometry. Journal of Geophysical Research, 111, B12402. https://doi.org/10.1029/2005JB004014

Taylor, M., \& Yin, A. (2009). Active structures of the Himalayan-Tibetan orogen and their relationships to earthquake distribution, contemporary strain field, and Cenozoic volcanism. Geosphere, 5(3), 199-214.

Tymofyeyeva, E., \& Fialko, Y. (2015). Mitigation of atmospheric phase delays in InSAR data, with application to the eastern California shear zone. Journal of Geophysical Research: Solid Earth, 120, 5952-5963. https://doi.org/10.1002/2015JB011886

Van Der Woerd, J., Tapponnier, P., Ryerson, F. J., Meriaux, A.-S., Meyer, B., Gaudemer, Y., et al. (2002). Uniform postglacial slip-rate along the central $600 \mathrm{~km}$ of the Kunlun fault (Tibet), from ${ }^{26} \mathrm{Al},{ }^{10} \mathrm{Be}$, and ${ }^{14} \mathrm{C}$ dating of riser offsets, and climatic origin of the regional morphology Geophysical Journal International, 148(3), 356-388.

Wadge, G., Webley, P., James, I., Bingley, R., Dodson, A., Waugh, S., et al. (2002). Atmospheric models, GPS and InSAR measurements of the tropospheric water vapour field over Mount Etna. Geophysical Research Letters, 29(19), 1905. https://doi.org/10.1029/2002GL015159

Wallace, K., Yin, G., \& Bilham, R. (2004). Inescapable slow slip on the Altyn Tagh fault. Geophysical Research Letters, 31, L09613. https://doi.org/10.1029/2004GL019724

Wang, C., Dai, J., Zhao, X., Li, Y., Graham, S. A., He, D., et al. (2014). Outward-growth of the Tibetan Plateau during the Cenozoic: A review. Tectonophysics, 621, 1-43.

Wang, H., \& Wright, T. (2012). Satellite geodetic imaging reveals internal deformation of western tibet. Geophysical Research Letters, 39, L07303. https://doi.org/10.1029/2012GL051222

Wang, H., Xu, C., \& Ge, L. (2007). Coseismic deformation and slip distribution of the $1997 M_{w} 7.5$ Manyi, Tibet, earthquake from InSAR measurements. Journal of Geodynamics, 44(3), 200-212.

Wang, W., Qiao, X., Yang, S., \& Wang, D. (2017). Present-day velocity field and block kinematics of Tibetan Plateau from GPS measurements. Geophysical Journal International, 208(2), 1088-1102.

Washburn, Z., Arrowsmith, J. R., Forman, S. L., Cowgill, E., Xiaofeng, W., Yueqiao, Z., et al. (2001). Late Holocene earthquake history of the central Altyn Tagh fault, China. Geology, 29(11), 1051-1054.

Wasowski, J., \& Bovenga, F. (2014). Investigating landslides and unstable slopes with satellite multi temporal interferometry: Current issues and future perspectives. Engineering Geology, 174, 103-138.

Webley, P., Bingley, R., Dodson, A., Wadge, G., Waugh, S., \& James, I. (2002). Atmospheric water vapour correction to InSAR surface motion measurements on mountains: Results from a dense GPS network on Mount Etna. Physics and Chemistry of the Earth, Parts A/B/C, 27(4), $363-370$

Wen, Y., Li, Z., Xu, C., Ryder, I., \& Bürgmann, R. (2012). Postseismic motion after the $2001 M_{w} 7.8$ Kokoxili earthquake in Tibet observed by InSAR time series. Journal of Geophysical Research, 117, B08405. https://doi.org/10.1029/2011JB009043

Wessel, P., \& Smith, W. H. (1991). Free software helps map and display data. Eos, Trans. AGU, 72(41), $441-446$.

Williams, S., Bock, Y., \& Fang, P. (1998). Integrated satellite interferometry: Tropospheric noise, GPS estimates and implications for interferometric synthetic aperture radar products. Journal of Geophysical Research, 103(B11), 27,051-27,067.

Wimpenny, S., Copley, A., \& Ingleby, T. (2017). Fault mechanics and post-seismic deformation at Bam, SE Iran. Geophysical Journal International, 209(2), 1018-1035.

Wittlinger, G., Tapponnier, P., Poupinet, G., Mei, J., Danian, S., Herquel, G., \& Masson, F. (1998). Tomographic evidence for localized lithospheric shear along the Altyn Tagh fault. Science, 282(5386), 74-76.

Wittlinger, G., Vergne, J., Tapponnier, P., Farra, V., Poupinet, G., Jiang, M., et al. (2004). Teleseismic imaging of subducting lithosphere and Moho offsets beneath western Tibet. Earth and Planetary Science Letters, 221(1), 117-130.

Wright, T. J., Parsons, B., England, P. C., \& Fielding, E. J. (2004). InSAR observations of low slip rates on the major faults of western Tibet. Science, 305(5681), 236-239.

Xu, X., Wang, F., Zheng, R., Chen, W., Ma, W., Yu, G., et al. (2005). Late quaternary sinistral slip rate along the Altyn Tagh fault and its structural transformation model. Science in China Series D: Earth Sciences, 48(3), 384-397.

Yin, A., \& Harrison, T. M. (2000). Geologic evolution of the Himalayan-Tibetan orogen. Annual Review of Earth and Planetary Sciences, 28(1), $211-280$.

Yuan, D.-Y., Ge, W.-P., Chen, Z.-W., Li, C.-Y., Wang, Z.-C., Zhang, H.-P., et al. (2013). The growth of northeastern Tibet and its relevance to large-scale continental geodynamics: A review of recent studies. Tectonics, 32, 1358-1370. https://doi.org/10.1002/tect.20081

Yun, S.-H., Zebker, H., Segall, P., Hooper, A., \& Poland, M. (2007). Interferogram formation in the presence of complex and large deformation. Geophysical Research Letters, 34, L12305. https://doi.org/10.1029/2007GL029745

Zhang, L., Ding, X., Lu, Z., Jung, H.-S., Hu, J., \& Feng, G. (2014). A novel multitemporal InSAR model for joint estimation of deformation rates and orbital errors. Geoscience and Remote Sensing, IEEE Transactions on, 52(6), 3529-3540.

Zhang, P.-Z., Shen, Z., Wang, M., Gan, W., Bürgmann, R., Molnar, P., et al. (2004). Continuous deformation of the Tibetan Plateau from global positioning system data. Geology, 32(9), 809-812.

Zhu, S., Xu, C., Wen, Y., \& Liu, Y. (2016). Interseismic deformation of the Altyn Tagh fault determined by interferometric synthetic aperture radar (InSAR) measurements. Remote Sensing, 8(3), 233. 